\title{
El dislocamiento de la elite. El caso de las confiscaciones revolucionarias en Durango
}

Graziella Altamirano Cozzi

INSTITUTO MORA

En este texto se analiza cómo fue afectada la elite porfiriana de Durango durante el movimiento revolucionario, principalmente a través del proceso confiscatorio de sus bienes y propiedades llevado a cabo por las distintas facciones que controlaron el estado.

La hora de la justicia ha sonado. Temblad, vosotros los poderosos porque el pueblo, el pueblo que tanto explotasteis, no quiere ya tiranos y reclama en los campos de batalla sus santas libertades y sus sacrosantos derechos.

Durango, febrero $1914 .^{1}$

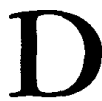

urante los últimos años del porfiriato, el estado de Du. rango estuvo prácticamente regido por una elite integrada por un exclusivo grupo de familias vinculadas por lazos económicos y de parentesco,

${ }^{1}$ La Unión Liberal, 1 de marzo de 1914. cuyos miembros figuraron en las altas esferas del poder político y mantuvieron el control de la economía al concentrar intereses en la agricultura, la ganadería, la industria, el comercio y las finanzas. Tras el estallido de la revolución, el descontento popular y la rebelión en el campo habrían de significarse como una respuesta a las formas de autoridad y dominio encarnadas por esta oligarquía, en su mayoría terrateniente.

La revolución en Durango, caracterizada como un vigoroso movimiento de corte social con demandas agrarias radicales, reflejó desde sus inicios la 
marcada inconformidad prevaleciente en las áreas rurales de la entidad, producto de las disputas por tierras que existían entre algunas congregaciones y las haciendas vecinas. La creciente agitación popular impulsada por circunstancias de carácter local que fueron aglutinadas por el maderismo, apuntó invariablemente contra los poderosos del antiguo régimen. Uno de los procedimientos que desde los primeros meses de la revuelta empezó a minar el poder de la oligarquía terrateniente, fue la apropiación de tierras y la destrucción de haciendas, las cuales se convertirían en el blanco de un ajuste de cuentas cobrado, en gran medida, a través de la ocupación, el saqueo, el robo y la expropiación.

Las disputas locales por derechos de tierras contaban con un largo historial en el que abundaban las reclamaciones, los litigios, los robos y el uso de la fuerza. Como resultado de estos antecedentes, a partir del estallido y a lo largo de la lucha armada, la gran propiedad se vio afectada a través de diferentes vías: destacaron las expropiaciones de facto, como expresión de demandas agrarias por reivindicaciones específicas, manifestadas a través de acciones autónomas de ocupación que se basaron en la fuerza de las armas; también se reflejaron los resentimientos y la venganza en la explosión popular que destruyó e incendió muchas de las haciendas. Pero al mismo tiempo, por la vía oficial y para tratar de poner coto a esos procedimientos, se confiscaron propiedades rústicas y urbanas a través de decretos expedidos por los distintos gobiernos revolucionarios que controlaron el estado.
Con todo ello, no sólo se llegó a erosionar el poder económico que detentaba la oligarquía, sino que además, con las ganancias obtenidas por aquellas vías, se contribuyó al financiamiento de la guerra y, sobre todo durante el régimen villista, se vio un claro intento por colocar a las clases populares como las beneficiarias principales del gobierno. Cabe destacar que durante las distintas fases de la guerra también fueron muy frecuentes los despojos y confiscaciones aplicados a capricho de algunos jefes revolucionarios y comandantes militares, quienes abusaron del poder conferido por la facción en turno, actuando sin la autorización del gobierno local.

Estas páginas tienen como propósito abordar el proceso confiscatorio de la gran propiedad en Durango y detectar la forma como fue afectada la elite durangueña, a través del examen de la actuación de los distintos gobiernos que controlaron la entidad durante la lucha armada (constitucionalista y, después de la escisión revolucionaria, villista y carrancista), así como tratar de demostrar, con los datos documentales hasta ahora récabados, en qué medida esa elite fue desarticulada por cada uno de dichos regímenes; qué grado de afectación sufrió en sus intereses y, finalmente, en qué posición quedó al término de la revolución.

\section{"AJUSTE DE CUENTAS" POR VIEJOS AGRAVIOS (FEBRERO DE 1911 A JUNIO DE 1913)}

Los conflictos por tierras que las comunidades rurales, sobre todo del este de 


\section{SECUENCIA}

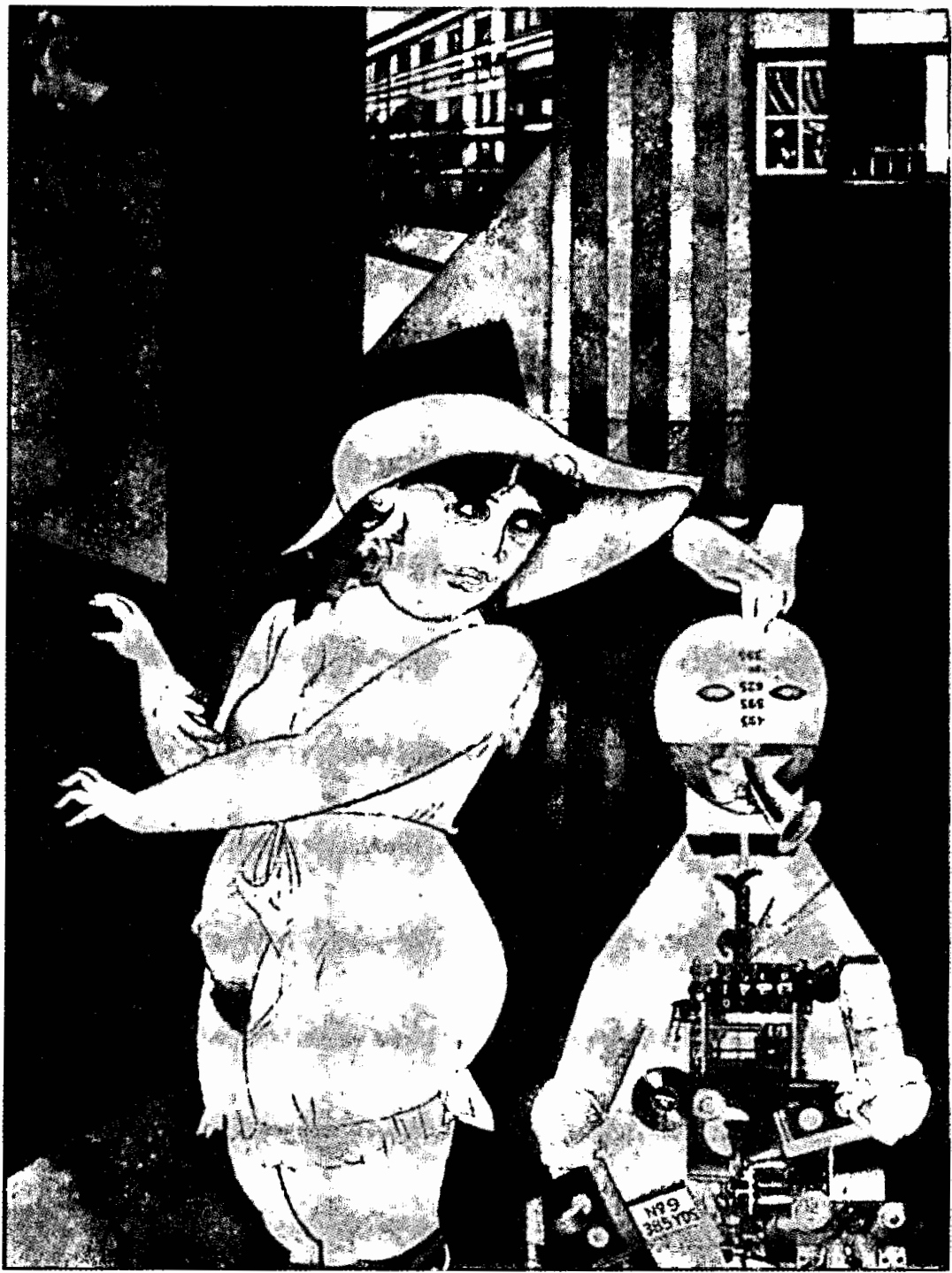


Durango, venían teniendo de tiempo atrás con los grandes hacendados y que durante los últimos años del porfiriato se habían manifestado como una activa lucha organizada, se convirtieron al inicio de la revolución en acciones legitimadas por la participación de grupos agrarios en el movimiento armado, lo que llevó a algunos pueblos y congregaciones a recuperar por su propia mano aquello que reclamaban. La ocupación de tierras y propiedades por miembros de pueblos protagonistas de añejos pleitos con los dueños de las haciendas vecinas fue una demostración de justicia aplicada a través de prácticas autogestivas para recobrar lo usurpado.

Los casos más representativos al respecto fueron el de la congregación de El Arenal, en el municipio de Durango, cuyos habitantes tomaron posesión de los terrenos de que habían sido despojados por los dueños de las haciendas de Navacoyán y San Lorenzo del Aire, Felipe Pérez Gavilán y Francisco Gómez Palacio, respectivamente; ${ }^{2}$ también las congregaciones de La Uña y El Conejo, en el partido de Nazas y el pueblo de Peñón Blanco, en el partido de Cuencamé, cuyos vecinos ocuparon tierras y repartieron terrenos de riego pertenecientes a las estancias de la gran hacienda de Santa Catalina del Álamo, propiedad de la familia Martínez del Río; ${ }^{3}$ así como los vecinos del antiguo presidio de El Pasaje, el cual al paso del

${ }^{2}$ Archivo General de la Nación (en adelante AGN), Comisión Nacional Agraria, Resoluciones presidenciales, vol. 1, fs. 121-123.

${ }^{3}$ Archivo General Agrario (en adelante AGA), Terrenos nacionales. Ejidos, 1.24 (07), exp. 34, leg. 2, junio de 1912 . tiempo había quedado comprendido dentro de este mismo latifundio y cuyos habitantes ocuparon sus antiguas tierras, aguas, casas y montes, dividiendo y cultivando por su cuenta los terrenos de labor "que debían ser para el pueblo". ${ }^{4}$ En el mismo caso se encontraban los aguerridos pueblos unidos de Santiago y San Pedro Ocuila, en el municipio de Cuencamé, quienes se posesionaron de las tierras de la hacienda de Sombreretillos, propiedad de los López Negrete, que por años habían tratado de recuperar legalmente. ${ }^{5}$

Al triunfo de la revolución maderista en Durango, el nuevo régimen preservó muchas de las viejas estructuras del aparato porfiriano y dio prioridad a la resolución de los conflictos políticos y electorales del momento, dejando postergada la solución de las demandas sociales locales. ${ }^{6}$ En este periodo, la inconformidad de un buen número de ex combatientes se volcó contra el gobierno que ellos mismos habían ele. vado al poder, lo que dio una nueva vitalidad al movimiento popular, agravó las tensiones y atizó el descontento en muchas partes del estado, en donde

${ }^{4}$ AGN, Comisón Nacional Agraria, Resoluciones presidenciales, vol. trv, f. 421 ; El Criterio, 24 de abril de 1912. Esta hacienda ocupaba en mayor proporción el partido de Cuencamé, pero también se extendía a los partidos vecinos de Nazas y San Juan del Río.

5 "Demanda civil promovida por los indígenas de Santiago y San Pedro Ocuila representados por el señor Severino Ceniceros, en contra de la señora Petra Salcido, viuda de López Negrete", Cuencamé, Durango, 1912 (copia procedente del Archivo de Cuencamé proporcionada por Antonio Avitia). Para ubicar los partidos y las cabeceras municipales véase el mapa adjunto.

"Véase Altamirano, "Maderismo", 1999. 
Mapa 1. El estado de Durango. Los trece partidos y cabeceras municipales según la ley territorial de 1905

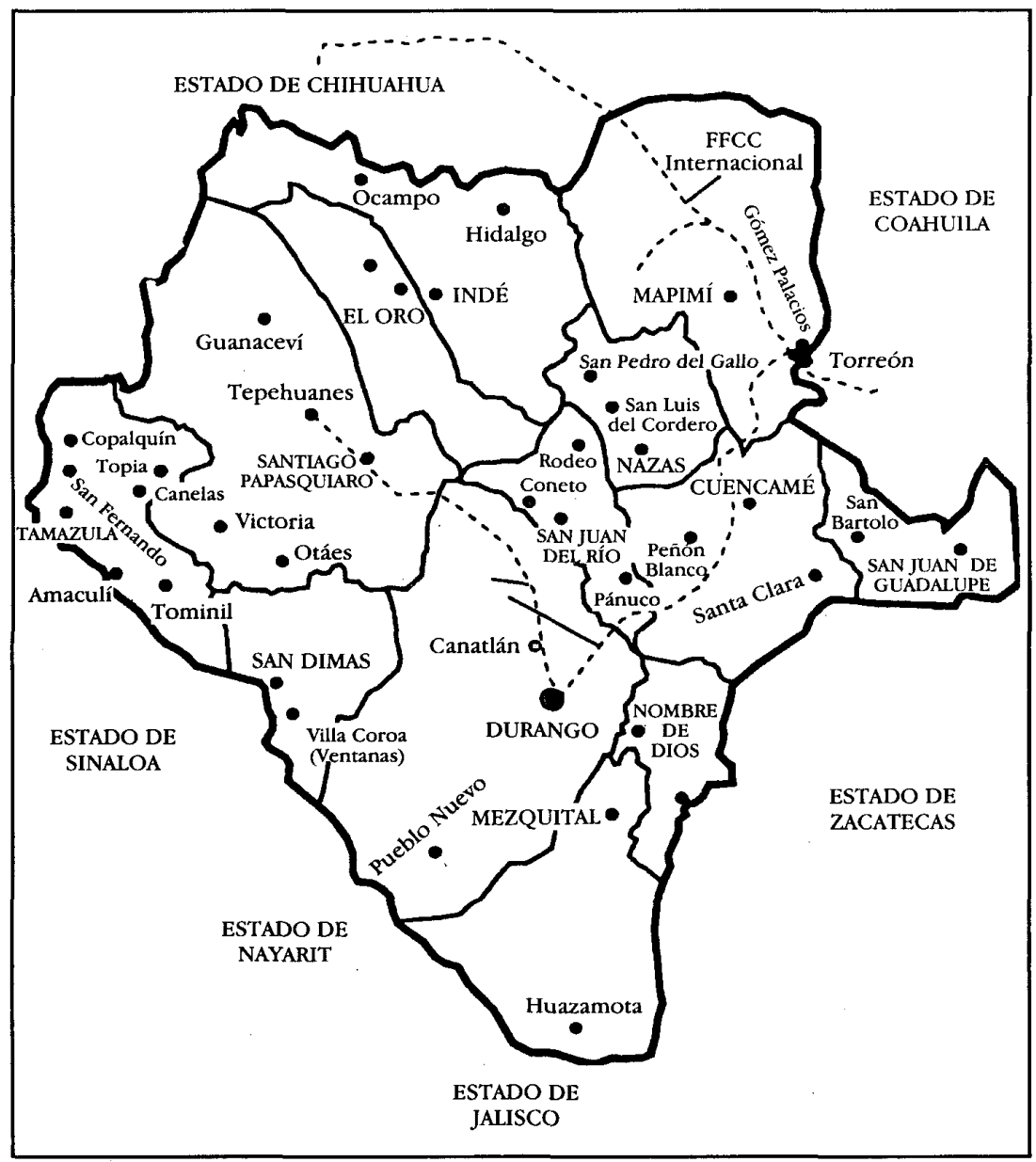

Fuente: Mapoteca "Manuel Orozco y Berra", Dirección General del Servicio Meteorológico Nacional de la SARH. 
las esperanzas defraudadas se tradujeron en revueltas y motines que, en muchos casos, al cobijo de banderas como la orozquista, produjeron una violencia incontenible.

Esta nueva ola de efervescencia se tradujo en múltiples actos justicieros producto de la inconformidad de grupos heterogéneos que aglutinaron resentimientos de muy diversa índole, como los reclamos de peones y arrendatarios, sobre todo de las grandes haciendas del partido de Cuencamé, y que se reflejaron en los excesos que cometieron algunas partidas de rebeldes, combinadas en ocasiones con las fuerzas orozquistas procedentes de Chihuahua, al saquear, destruir y quemar muchas de las grandes haciendas del estado, que eran para ellos el símbolo del poder de los latifundistas. Las huestes del orozquista Cheché Campos y otros grupos inconformes hicieron de estas fincas el blanco principal de sus ataques, como la de Santa Catalina del Álamo y sus estancias anexas, perteneciente a los Martínez del Río; ${ }^{7}$ la de La Purísima, de Miguel García, "saqueada bárbaramente"; El Ojo y El Saucillo, de la familia Curbelo, devastadas e incendiadas y los guardias y empleados, ejecutados; Sombreretillos, de los López Negrete, arrasada "sin dejar piedra sobre piedra", ${ }^{8}$ y la hacienda de Juan Pérez, propiedad de la familia Moncada, "donde los empleados fueron ajusticiados". ${ }^{9}$ Cuando el gobierno de Madero

\footnotetext{
7 Véase Walker, "Homegrown", 1992.

${ }^{8}$ El Mañana, 7 de mayo de 1912.

${ }^{9}$ Informe del cónsul Hamm, Durango, 30 de noviembre de 1912, citado por Knight, Revolución, 1996, vol. I, p. 335.
}

fue derrocado por el golpe militar de Huerta, en febrero de 1913, sólo un puñado de haciendas en Durango continuaba trabajando. ${ }^{10}$

Después de la agitación en que se vio envuelto el campo durangueño durante los gobiernos maderistas, los grandes terratenientes y destacados personajes de la antigua elite porfirista amenazados en sus intereses, vislumbraron, con la llegada de Victoriano Huerta al poder, la posibilidad real de recuperar la condición económica que tenían antes de la revolución, así como sus propiedades y de afianzar sus posiciones y privilegios. Sin embargo, sus esperanzas se verían desvanecidas porque la rebelión social se vería reactivada con nuevos bríos, inmediatamente después del golpe de Estado huertista.

Discrepando a nivel regional de los ritmos que siguió la revolución en otras partes del país, Durango derrotó al huertismo a escasos cuatro meses del cuartelazo, al mismo tiempo que la revuelta agraria se ponía claramente de manifiesto. Por este tiempo muchas comunidades rurales, sin un control y una dirección centralizadas, formaron milicias locales encabezadas por los antiguos líderes populares del movimiento iniciado en 1910 y casi todo el estado, con excepción de las ciudades laguneras de Gómez Palacio y Lerdo -que serían tomadas poco más tarde-, quedó en poder de la revolución constitucionalista.

Por otra parte, en Durango la lucha iniciada contra el huertismo no fue encabezada por jefes enviados directamente por Venustiano Carranza como

\footnotetext{
${ }^{10}$ Walker, "Homegrown", 1992, p. 267.
} 
en otros estados del norte, sino por grupos autónomos durangueños de veteranos maderistas procedentes de distintas partes de la entidad, como Calixto Contreras y Severino Ceniceros, de Cuencamé; Orestes Pereyra, de La Laguna; Matías Pazuengo y los hermanos Arrieta, de la región occidental de la sierra, quienes tomaron las armas y mantuvieron por un tiempo cierta independencia de la dirección carrancista. Cuando en marzo de 1913 Carranza lanzó en el vecino estado de Coahuila el Plan de Guadalupe contra la usurpación de Huerta, los duranguenses ya estaban en pie de lucha $y$, al poco tiempo, el 18 de junio de 1913, ocupaban la capital del estado, unificados bajo el mando de Tomás Urbina, enviado por el general Villa, quien controlaba gran parte de Chihuahua. Fue entonces cuando los principales dirigentes durangueños reconocieron oficialmente el Plan de Guadalupe, incorporándose al constitucionalismo.

Durante los cuatro meses del gobierno huertista en la entidad, se había formado en la ciudad de Durango, $a$ instancias de prominentes miembros de la elite durangueña -entre quienes se encontraban los ricos hacendados y empresarios Julio Bracho, Francisco Gómez Palacio y Juan Gurrola-, un cuerpo de voluntarios integrado por miembros de las más influyentes familias de la sociedad, así como de empleados de las oficinas del gobierno, comerciantes y elementos simpatizantes de la nueva administración que apoyaban a Huerta. Esta agrupación, denominada Defensa Social, tuvo una destacada participación en el rechazo al primer ataque a la ciudad que los revolucionarios intentaron en el mes de abril. A partir de entonces y tomándose atribuciones de guardia nacional, la nueva corporación desató una tenaz persecución contra los maderistas civiles, etiquetándolos de "porristas", y efectuando arrestos, cateos y hasta fusilamientos. La Defensa Social llegó a contar con más de 700 miembros, en su gran mayoría civiles que recibieron instrucción militar y que fueron obligados por el gobierno a proporcionarle armas y municiones. Pertenecieron a ella "desde los más encumbrados personajes hasta sus más humildes empleados, formando una falange en auxilio a las fuerzas federales". ${ }^{11}$ Sus principales integrantes permanecerían en la mira de las distintas facciones revolucionarias que controlaron el estado a lo largo de la lucha. Fueron juzgados como "enemigos de la causa", siendo objeto de castigos y persecuciones por haber apoyado al huertismo.

A partir de la toma de la capital, en junio de 1913, considerada como uno de los asaltos más violentos y cruentos sufridos a manos de la revolución, comenzaron las disposiciones oficiales para castigar a la antigua elite porfiriana. Las acciones que antes se habían desatado contra los "porristas" maderistas, se revirtieron entonces. Empezaron las persecuciones contra aquellos que habían pertenecido al cuerpo de Defensa Social apoyando al huertismo; se impusieron multas y castigos financieros a los ricos considerados enemigos de la revolución y se iniciaron las confiscaciones de sus propiedades.

\footnotetext{
${ }^{11}$ Rouaix, Revolución, 1931, p. 23.
} 
El gobierno de Pastor Rouaix.

CONTRA "LOS ENEMIGOS DE LA

CAUSA" (JUNIO DE 1913 A AGOSTO

DE 1914)

Con el triunfo de la revolución constitucionalista en Durango, el movimiento durangueño, inserto ya en el área de dominio de Pancho Villa, se mantuvo sobre una base social conformada por numerosas comunidades agrarias de la entidad, las cuales constituirían un soporte vital de las fuerzas armadas que, convertidas en una parte significativa de la División del Norte villista, derrotaría en varias ocasiones al ejército federal en La Laguna, centro ferroviario estratégico y escenario de las principales campañas militares.

Después de tomar la capital, los principales dirigentes durangueños llevaron a cabo una "elección provisional popular", en la que resultó electo como gobernador del estado, el ingeniero Pastor Rouaix, profesionista de clase media y antiguo partidario de Madero que había ocupado importantes cargos públicos durante el régimen maderista en la entidad y que ahora, al frente del gobierno provisional constitucionalista y con la autoridad que le otorgaran los caudillos revolucionarios, se propondría poner en práctica los principales postulados de la revolución.

Si bien Rouaix recibió las riendas del gobierno por elección mayoritaria de los dirigentes populares que se habían levantado en armas desde 1910 , tuvo que hacer frente a las dificultades que se suscitaron con dichos caudillos, viéndose en la necesidad de controlar a algunos jefes militares que habían ocupado puntos claves de la entidad y donde ellos mismos o sus subordinados cometían abusos de autoridad e incurrían en excesos contra propietarios y propiedades. En este sentido, Rouaix trató por todos los medios de frenar las expropiaciones de facto y hacer respetar las garantías, sobre todo en las grandes haciendas, a las que se vio precisado a proporcionarles guerrillas de protección para que se pudieran reanudar cuanto antes los trabajos agrícolas; esta era una de sus principales preocupaciones para que la economía estatal se recuperara. Intentó allanar las diferencias que surgieron entre los generales Tomás Urbina y Domingo Arrieta, quienes pretendían mantener el control exclusivo de sus respectivas zonas de operaciones y que no coincidían con el nombramiento de autoridades civiles y jefes de armas. Para el nuevo gobernador tales desacuerdos ponían en peligro la unidad revolucionaria en momentos en que había que hacer causa común contra el enemigo huertista y cuando la campaña en la región requería la mejor armonía entre las fuerzas constitucionalistas. Todo ello representaba un escollo mayor para el gobierno, pues tuvo que reforzar el control de las acciones de mando individuales emprendidas por aquellos generales; mediar entre jefes políticos y militares y, sobre todo, hacer respetar las propiedades y devolver los productos robados de las fincas. ${ }^{12}$

12 Rouaix a Carranza, 29 de septiembre de 1913 y Rouaix a Urbina, 1 de noviembre de 1913 , Archivo Histórico del Gobierno del Estado de Durango (en adelante AHGED), Libro copiador del gobernador Pastor Rouaix, 1913-1914. 
Una constante preocupación de Rouaix fue proporcionar seguridad a los extranjeros y sus propiedades, en especial a los estadunidenses. ${ }^{13}$ Opinaba que las garantías dadas por su gobierno eran mayores que las que ofrecía Huerta, motivo por el cual, Estados Unidos veía con simpatía la causa de la revolución y apoyaba el movimiento. Recomendaba insistentemente evitar todo motivo de reclamación por parte de los ciudadanos estadunidenses para que no menguara la confianza que su gobierno tenía en el movimiento constitucionalista, y solucionar las dificultades existentes a fin de que sus intereses sufrieran lo menos posible. No obstante, para impedir complicaciones con los extranjeros residentes en el estado que pudieran ocasionar un conflicto de

${ }^{13}$ Rouaix a C. Contreras, 27 de diciembre de 1913; Rouaix a E. Nájera recomendándole que no tome reses de las propiedades de los súbditos alemanes Hintze, Weber y Rapp, 8 de enero de 1914; Rouaix a D. Arrieta pidiendo garantías en la propiedad del alemán Kurt Varon von Knesebeck que tenía una vinata establecida en la hacienda La Joya para que no se sacaran los productos por orden de autoridades militares, 2 de marzo de 1914; a Severino Ceniceros pidiendo garantías para la hacienda de La Estanzuela, propiedad de extranjeros, 19 de marzo de 1914; Rouaix a D. Arrieta ordenando que se le proporcione una guerrilla al ciudadano estadunidense Homer $C$. Coen, arrendatario de la hacienda de Güichapa, en el Rodeo, 9 de marzo de 1914; Rouaix a A. Laveaga, en San Dimas expresándole que, dado el ascendiente que tiene en esa región, facilite la protección a los estadunidenses de las minas La Candelaria y San Luis, 14 de marzo de 1914; ante los reclamos del vicecónsul alemán por la extracción de madera en una compañía y del cónsul estadunidense Hamm por atropellos sufridos en la Cía. de Velardeña, ofrece garantías a los ciudadanos estadunidenses. Ibid. carácter internacional, prohibió temporalmente que personas o compañías foráneas adquirieran bienes raíces y trató de controlar los contratos de arrendamiento. ${ }^{14}$

Una vez que se pudieran controlar las revueltas locales y las expropiaciones de facto, lo más apremiante para el nuevo gobernador era empezar a dar solución de una manera oficial, a través del trámite agrario, a las distintas demandas de tierras. Ello tuvo como resultado una temprana legislación agraria estatal que influiría posteriormente en el diseño del programa del carrancismo y que serviría como base de las formas de organización eminentemente agraristas que se manifestarían después en la entidad.

Pastor Rouaix, futuro secretario de Agricultura de Carranza y uno de los principales redactores del artículo 27 constitucional, comprendiendo la fuerza de las demandas agrarias que habían mantenido al campo durangueño en efervescencia y procurando una política de pacificación con los grupos en rebeldía, expidió, en octubre de 1913, una ley agraria estatal, mientras en otras partes del país se continuaba en plena lucha contra el huertismo.

Para el nuevo gobernador, la piedra angular del problema del campo en Durango era el poder de los grandes terratenientes, quienes habían monopolizado el suelo del estado y propiciado la falta de tierras particulares, por lo que las clases rurales no habían tenido otro medio de subsistencia que servir de peones en las haciendas. ${ }^{15}$

\footnotetext{
${ }^{14}$ Colección, 1917, p. 73.

${ }^{15}$ Ibid., p. 61.
} 


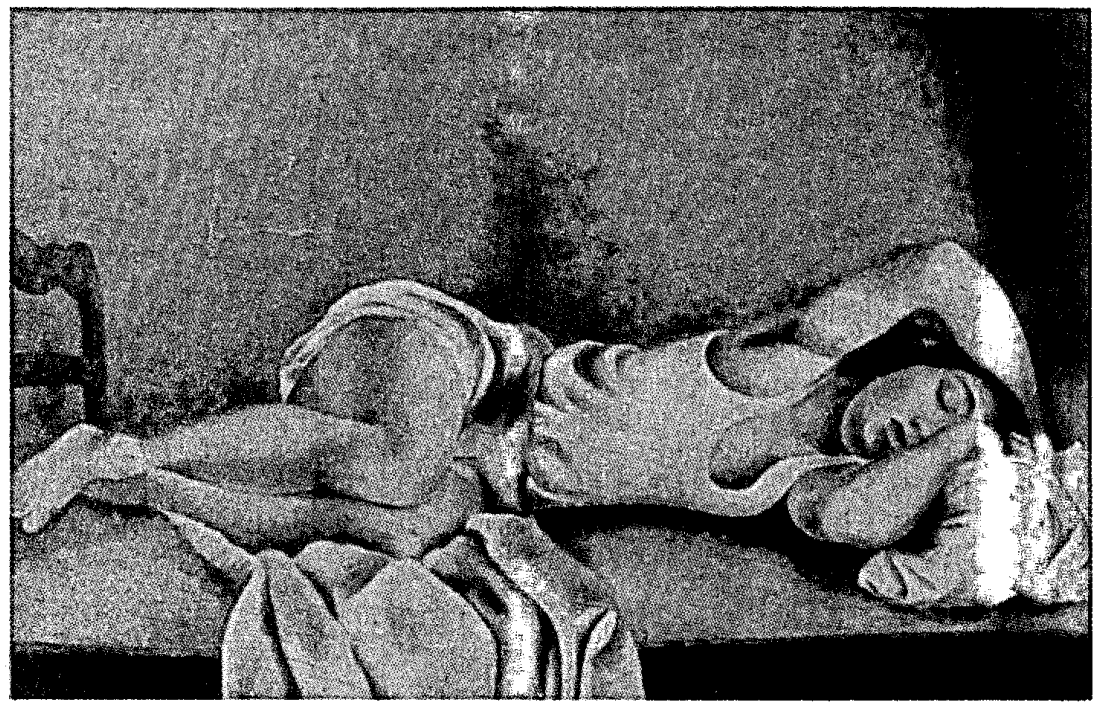

La inmediata expedición de la ley agraria reflejaba su preocupación por iniciar la reforma del régimen económico y social existente, pero al mismo tiempo pretendía contener la ola de revueltas que cubría varias zonas de la entidad, así como contar con el apoyo y respaldo de las clases populares en medio de la inseguridad en que se encontraba el estado ante las intenciones huertistas de recuperarlo.

La ley agraria de Rouaix concedía a los pueblos que carecían de tierras una superficie proporcional al número de sus habitantes, al mismo precio que el gobierno la adquiriera. Los terrenos serían expropiados de las haciendas inmediatas a los pueblos o congregaciones que los solicitaran, "siempre que la superficie que quedara a aquéllas des- pués de hecha la expropiación excediera de 5000 hectáreas". Asimismo, disponía que en caso de que no se llegara a un acuerdo entre el gobierno y los dueños de los terrenos para su adquisición, el mismo gobierno solicitaría su expropiación, previa evaluación para fijar el monto de la indemnización. La superficie adjudicada a cada vecino del pueblo no sería mayor de 30 hectáreas, y en todos los repartos el gobierno se reservaría un lote para establecer una Escuela Experimental de Agricultura o para los usos que convinieran. Erigiría nuevos pueblos en los lugares que lo juzgara necesario, tomando una superficie de 2000 hectáreas, de la que una parte sería destinada al fundo del pueblo. ${ }^{16}$

${ }^{16}$ Ibid. 
Esta ley, sin embargo, era limitada. No se refería ni a la gran división de las propiedades, ni a la dotación o restitución de tierras a las congregaciones y pueblos que habían sido despojados por los dueños de las haciendas vecinas. Al poco tiempo de su expedición, se fundó un nuevo pueblo en el partido de Cuencamé, denominado Villa Madero, el cual fue formado con 100 hectáreas que se tomaron de la hacienda de San Gabriel divididas en lotes cuadrados de $\mathbf{8 4}$ metros, y con terrenos de la hacienda de Tapona, propiedad de Teodora Pastor Moncada, viuda de Blanco, para los ejidos del pueblo. ${ }^{17}$ La ley agraria sería complementada por Rouaix con otras disposiciones, como los decretos de expropiación por causa de utilidad pública; de intervención y explotación de fincas por parte del gobierno, en ausencia de sus propietarios; así como de confiscación de los bienes del clero.

Si bien durante los primeros meses del gobierno de Rouaix muchos miembros de la elite salieron del estado por el peligro que corrían sus intereses, otros permanecieron en él, quizá con el fin de no perder sus propiedades rústicas, confiados en el ofrecimiento del gobernador de proteger, sobre todo, las de aquellos dueños de haciendas agrícolas que estuvieran dispuestos a reanudar cuanto antes la producción en sus tierras. En un principio, Rouaix no actuó directamente contra la elite terrateniente, y llama la atención el cuidado que tuvo para que estas fincas fueran respetadas en función de su

${ }^{17}$ Ibid., p. 68. rendimiento y la reanudación de sus trabajos de campo. ${ }^{18}$

En este sentido, Rouaix supo aprovechar la permanencia en Durango de algunos miembros de la oligarquía, procurando mantenerlos bajo su control. Para ello, y ante la escasez de numerario que dificultaba cada vez más las operaciones mercantiles y el pago de contribuciones, una de las medidas tomadas por su gobierno para resolver las necesidades económicas más apremiantes fue la emisión de bonos de carácter local y de duración indefinida mediante la asociación del gobierno con los principales capitalistas durangueños, quedando éstos obligados por contrato a prestar al primero, en caso de que lo solicitara, para cubrir sus gastos. Para esta transacción, que en realidad era la imposición de un préstamo forzoso, dichos capitalistas constituyeron una agrupación, la Asociación de Durango, la cual quedó como responsable de la liquidación final del papel

${ }^{18}$ Rouaix a E. Nájera, agosto 21 de 1913, pidiendo que fueran devueltos al licenciado Antonio Bracho los animales de la ordeña que le sustrajeron de su hacienda La labor de Guadalupe y se le proporcionara una guerrilla en atención a los muy graves perjuicios sufridos por dicha propiedad; Rouaix a D. Arrieta pidiendo devolver al licenciado Jaime Gurza, correligionario víctima de las persecuciones de Huerta, las reses sustraídas de su hacienda Juana Guerra y que en lo sucesivo se respete dicha hacienda, 13 de noviembre de 1913; Rouaix a E. Nájera "suplicando" se libren órdenes para que le sean devueltas al señor Luis Pérez Gavilán las vacas paridas de su propiedad robadas de la estancia del registro, perteneciente a la hacienda de Navacoyán, para evitar que se pierdan las crías, 7 de diciembre de 1913. AHGED, Libro copiador del gobernador Pastor Rouaix, 1913-1914. 
en circulación, garantizándose ella misma como cualquier sociedad bancaria, esto es, con hipotecas, prendas, documentos por cobrar, etc., todo lo cual recibiría a cambio de préstamos hechos a particulares. ${ }^{19} \mathrm{El}$ gobierno, por su parte, se comprometía a procurar la circulación forzosa de estos bonos.

Entre los principales propietarios, comerciantes y hacendados que integraron la Asociación de Durango, se encontraban prominentes miembros de la elite, como Alberto y Antonio Gurza, Alberto y Ventura G. Saravia, Julio F. Curbelo, Juan Santa Marina, Julio Bracho, Tomás y Alejandro de la Parra, Luis Pérez Gavilán y Antonio Gómez Palacio. ${ }^{20}$

El convenio con el gobierno estipulaba que la nueva asociación se mantendría "desligada de todo carácter político", ya que su cooperación era solicitada solamente para "el sostenimiento del régimen social". ${ }^{21}$ Sin embargo, con esta medida Rouaix no sólo exigía a los principales propietarios, empresarios, comerciantes y banqueros el cumplimiento de un compromiso, sino que los obligaba a subordinarse al régimen y a contribuir en su estabilidad y en el mejoramiento de su economía, que se encontraba en una situación muy difícil.

Por su parte, los terratenientes, sobre todo aquellos que no negociaron con el gobierno pero que habían estado involucrados en las actividades de la Defensa Social, permanecerían en

\footnotetext{
${ }^{19}$ Rouaix a Carranza, 29 de septiembre de 1913, en ibid.

${ }^{20}$ Véase Colección, 1917 , pp. 20-27 y pp. 3234.

${ }^{21}$ Ibid., p. 23.
}

la mira de las nuevas autoridades. Debido al peligro que corrían sus intereses, muchos de ellos salieron del estado, por lo que Rouaix dispuso que las fincas abandonadas, tanto agrícolas como mineras o industriales, fueran explotadas con la intervención del gobierno estatal. ${ }^{22}$ Las confiscaciones se empezaron a hacer por ausencia de los propietarios, pero también porque éstos habían pertenecido al Cuerpo de Defensa Social y, por tanto, apoyado al huertismo, siendo considerados "enemigos de la causa". En este caso se encontraba Juan Gurrola, que fue presidente de ese cuerpo y que al salir del estado abandonó su hacienda de Tapias, en el partido de Durango, la cual fue intervenida inmediatamente por el gobierno. ${ }^{23}$

A quienes se los relacionó con la famosa Defensa Social, así como a los miembros del clero que los apoyaron, se les prohibió regresar a territorio durangueño sin el consentimiento del gobierno provisional. El decreto en cuestión los consideraba como "los contumaces enemigos de la revolución" que habían desplegado de una manera sistemática una política de apoyo en favor del gobierno usurpador, siendo evidente que obraban así "por creerlo más conveniente para la conservación de sus intereses y prescindiendo de toda consideración de patriotismo". ${ }^{24}$

\footnotetext{
${ }^{22}$ Ibid., p. 74.

${ }^{23}$ Juan Gurrola fue asesinado en el cuartel de San Cosme, en la ciudad de México, por fuerzas villistas en diciembre de 1914. AGN, ramo Gobernación, Periodo revolucionario, vol. 172 , exp. 58.

${ }^{24}$ Colección, 1917, p. 75.
} 
Si bien estas disposiciones iban dirigidas contra un grupo bien definido de la oligarquía, relacionado estrechamente con el Cuerpo de Defensa Social, la acción fundamental de Rouaix en este sentido se centró en contrarrestar el poder del clero católico en alianza con dicha oligarquía. Una de sus primeras medidas al respecto fue poner en vigor las Leyes de Reforma, olvidadas por las autoridades eclesiásticas y los ministros del culto católico debido a la complacencia de la administración anterior, por lo que dispuso su estricta observancia a través de una circular enviada a todos los jefes políticos y la publicación de dichas leyes en el Diario Oficial. ${ }^{25}$ Asimismo, prohibió que los sacerdotes usaran trajes talares, lo cual comunicó en correspondencia privada al deán José de Jesús Contreras, en ausencia del arzobispo, como "un deber penoso pero ineludible", que era el compromiso contraído con los revolucionarios, lo cual lo obligaba -decía- "a originarle la molestia que tal vez le infiera con tal indicación". ${ }^{26}$ Pese a que el deán accedió sin cortapisas a cumplir las órdenes del gobernador, poco después Rouaix expulsó a los sacerdotes de la Compañía de Jesús y prohibió la entrada al territorio de su mando a Francisco Mendoza y Herrera, arzobispo de Durango, actos que consideró como "casos especiales y en modo alguno $[\ldots]$ contra los demás miembros del clero". 27

${ }^{25}$ Ibid., p. 66.

${ }^{26}$ Rouaix a J. de J. Contreras, septiembre de 1913, en AHGED, Libro copiador del gobernador Pastor Rouaix, 1913-1914.

${ }^{27}$ Ibid., 4 de febrero de 1914.
Sin embargo, lo que en realidad empezó a minar considerablemente el poder económico que tenía la Iglesia en Durango y los miembros de la elite allegados a ella, fue el decreto expedido el 29 de julio de 1914, de adjudicación de los bienes del clero, el cual iba dirigido contra la Compañía de Enseñanza Industrial y Científica, S. A., cuyos integrantes eran, en su mayoría, sacerdotes y seglares católicos. ${ }^{28}$ Esta asociación se había fundado con el objeto de administrar el Seminario Conciliar de Durango y el Colegio Guadalupano de Ninas de Durango, y de llevar a cabo operaciones de inversión para la edición de libros y periódicos científicos y literarios; la creación de laboratorios y talleres para la enseñanza teórico-práctica de artes y oficios; el establecimiento de nuevos colegios para educar a la juventud; la inversión de dinero en préstamo, compra y arrendamiento de edificios o terrenos utilizables para los fines de la compañía; la venta de edificios y terrenos; la adquisición de muebles, así como la ejecución de operaciones que directa o indirectamente se relacionaran con el objeto principal de

${ }^{28}$ La ley de adjudicación de bienes del clero cita como integrantes de la Compañía de Enseñanza Industrial y Científica $\mathbf{S}$. A., al arzobispo Francisco Mendoza y Herrera, al obispo José de J. Guzmán, al canónigo José de J. Contreras, al obispo Vicente Castellanos, al canónigo Rafael López de Lara, al canónigo Agustín Escobar, al canónigo honorario Rosalío Morales, al canónigo Julio del Palacio, al presbítero Jesús María Castañeda y al presbítero José Heid, y a los archicofrades Juan Santa Marina, Antonio Gurza, Miguel Verduzco, Carlos Bracho, Julio Bracho y Ángel del Palacio, administrada por un consejo cuyo presidente era el arzobispo Mendoza y Herrera. Colección, 1917, p. 81. 
la sociedad y que fueran convenientes para la misma. ${ }^{29}$

El decreto de Rouaix contra los bienes del clero se basaba en las normas mencionadas por el artículo 27 de la Constitución vigente, referidas a las corporaciones e instituciones religiosas y civiles que, bajo patronato o administración de aquéllas o de ministros de algún culto, no tenían capacidad legal para adquirir en propiedad o administrar bienes raíces, ni capitales impuestos sobre estos bienes.

Gracias a esta disposición, pasaron a poder del estado "mientras se estableciera el gobierno general de la nación", los bienes raíces y los capitales impuestos que pertenecían a la Compañía de Enseñanza Industrial y Científica, los cuales se muestran en el cuadro 1.

Con este decreto se declaraban nulas y sin ninguna fuerza legal las enajenaciones de todo o parte de los bienes expresados, así como los gravámenes y cualquier clase de contratos hechos sobre ellos, previniendo a los deudores de los créditos mencionados de que, en lo sucesivo, no podían reconocer otro acreedor que el mismo estado, bajo la advertencia de hacer doble pago los que contravinieren la disposición.

Las propiedades de la Compañía de Enseñanza Industrial y Científica fueron controladas por la Administración de Bienes Intervenidos ${ }^{30} \mathrm{y}$ todas sus

\footnotetext{
${ }^{29}$ Registro Público de la Propiedad de Durango (en adelante RPPD), Sociedades y poderes, vol. 5, insc. 470, 25 de noviembre de 1912.

${ }^{30}$ Para 1919 las propiedades de la Compañía de Enseñanza seguían intervenidas y en 1921 fueron embargados los créditos y fincas urbanas
}

pertenencias confiscadas. Al canónigo Julio del Palacio, encargado de las oficinas del arzobispado, se le recogieron los libros, escrituras, estatutos y documentos de hipotecas y demás transacciones y operaciones verificadas por dicha compañía desde su fundación. Algunas casas confiscadas por el decreto de 29 de julio contenían muebles y útiles de las Escuelas Guadalupanas y otras estaban ocupadas por particulares que pagaban renta. Por órdenes de Rouaix se retiraron del Seminario Conciliar y de otras casas todo los libros, aparatos y demás objetos que pudieran ser utilizados en escuelas y oficinas del gobierno. ${ }^{31}$

Por su parte, el resto de los integrantes de la Compañía de Enseñanza Industrial y Científica de Durango que no habían aportado propiedades ni créditos hipotecarios, si bien no fueron in-

de la capital, con excepción de los créditos hipotecarios que pudieron ser cancelados.

${ }^{31}$ Fueron enviados al Instituto Juárez y a la Biblioteca del estado 7948 libros empastados, 2488 cuadernos, 145 bancas de madera, 109 pupitres, doce pizarrones, 64 sillas de madera, 25 escritorios, 17 libreros, una campana, un ábaco, una carretilla de fierro, once candiles para luz eléctrica, dos prensas para escritorio, un libro copiador nuevo, 35 mesas, 70 burós de madera, nueve tarimas, 113 cuadros y mapas, 86 lavamanos fijos y unidos, cuatro persianas, dos repisas, una caja fuerte, dos canastillas de alambre, dos escupideras, un bulto de manta trigueña usada, todos los armazones de la biblioteca, 77 roperos, dos escaleras, un cuadro de madera colgante con argollas para gimnasia, así como todos los aparatos de física, química y astronomía. Se recogieron 50.42 pesos en efectivo que había en la caja y se remitieron a fa Secretaría de Gobierno 63 resmas de papel para escritorio, 36 bultos de papel para imprenta y dos libreros con vidrios. AHGED, caja 205, 1913-1915. 
cluidos en este decreto de confiscación, según las evidencias documentales, sólo por el hecho de ser accionistas de dicha compañía se les incautaron sus propiedades particulares. En este caso se encontraban Carlos y Julio Bracho, Miguel Verduzco, Juan Santa Marina, Julio Curbelo y Ángel del Palacio, que como accionistas habían contribuido cada uno con 7000 pesos en efectivo, junto con otros miembros de la Iglesia católica, para completar el "fondo social" de la compañía. ${ }^{32}$

Pese al carácter legal que Rouaix trató de imprimir a todas sus disposiciones, muchas de las confiscaciones y ocupaciones que datan de la época de su gobierno no se hicieron a través de medidas oficiales dictadas desde el mismo, sino que fueron ordenadas directamente por los jefes militares, principalmente por la comandancia en manos del general Domingo Arrieta y sus subordinados. Después de la toma de la capital, las fuerzas revolucionarias ocuparon varias propiedades urbanas que sirvieron de cuarteles a los distintos cuerpos militares de los constitucionalistas y, posteriormente, villistas, arrietistas y carrancistas que transitaron por el estado. En este caso se encontraron la residencia del licenciado Francisco Gómez Palacio; el local comercial de La Francia Marítima (antes La Rebo-

\footnotetext{
32 El capital social formado por las aportaciones ascendía a 250000 pesos, suma que fue aumentada pocos meses después de la creación de la compañia, por la compra de algunas fincas urbanas en la capital. RPPD, Sociedades y poderes, vol. 5, insc. 470, 25 de noviembre de 1912; Propiedades, vol. 26, insc. 4569, 26 de diciembre de 1912; 4570, 27 de diciembre de 1912, y 4609,12 de febrero de 1913.
}

cería) del licenciado Miguel Verduzco; una casa de la señora Elodia Gurrola y otras propiedades que, durante los años de revolución, serían habitadas indistintamente por jefes militares, como una finca del clero que, cuando los villistas controlaron el estado, ocupó el general Sergio Pazuengo como propia, o la casa de Miguel Verduzco que, durante los gobiernos carrancistas, tuvo el general J. S. Novoa; la residencia de la señora Ángela Flores, esposa del ex gobernador porfirista, Juan Manuel Flores, ocupadà en esa misma época por el general carrancista Francisco Murguía, así como la del licenciado Juan Santa Marina, que sirvió como oficina del Depósito de Jefes y Oficiales de la 3a. Brigada. ${ }^{33}$

Del tiempo de Rouaix datan las intervenciones de la Compañía de Tranvías de Durango, la Fábrica El Tunal y la Fábrica de Harina El Porvenir, que fueron administradas por el gobierno y continuaron bajo su tutela hasta el término de la revolución, y hasta un molino de nixtamal, confiscado directamente por Domingo Arrieta. ${ }^{34}$

La Compañía de Tranvías, que funcionaba por tracción animal, fue intervenida en 1913 por orden expresa del general Domingo Arrieta, comandante de la plaza. Funcionó con buenos dividendos hasta mediados de 1915 y fue decayendo por escasez de inversión y mantenimiento, terminando por quedar fuera de servicio por falta de ani-

33 "Nota de las fincas urbanas con especificación de las fechas en que han sido ocupadas por diferentes fuerzas", $\mathrm{AGN}$, Bienes intervenidos, vol. SE, exp. 9.

${ }^{34}$ Ibid., vol. 6F, exp. 7. 


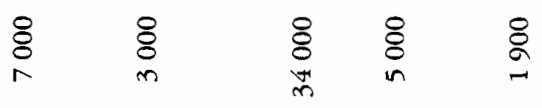

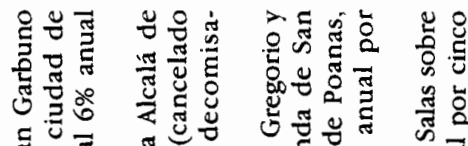

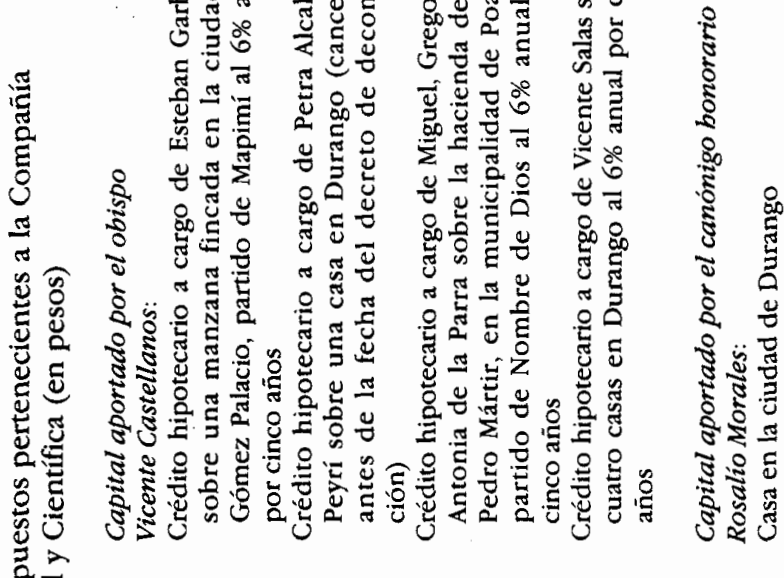



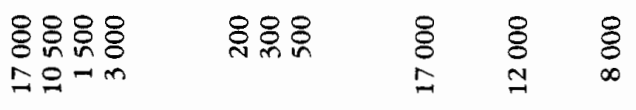

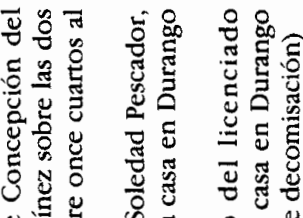

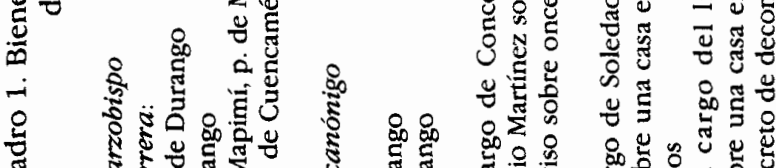

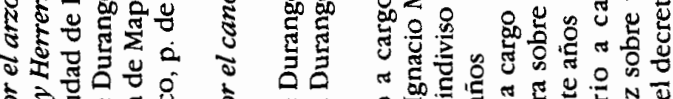

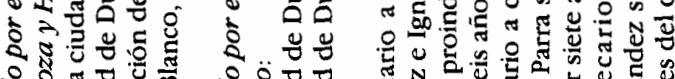

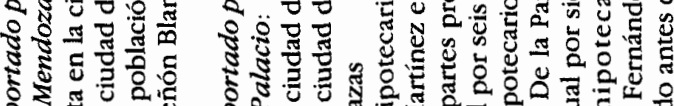

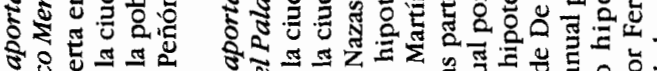

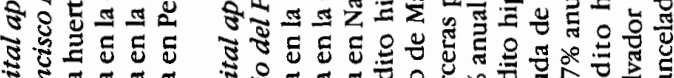

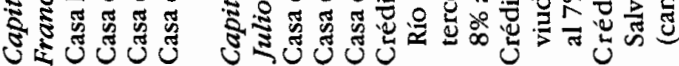




\section{SECUENCIA}

ร웜ำ

\begin{tabular}{l|l}
8 & 8 \\
8 & 8 \\
ㄴ. & 0 \\
& 0
\end{tabular}

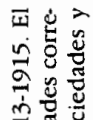

콩

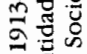

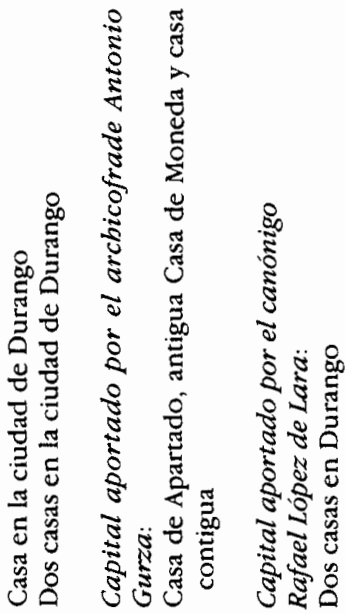

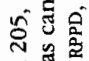

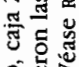

牙

递要

矛

पis

in 8

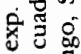

ลี

จุ่

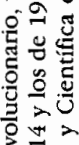

可娄

원

888
용은
0

ह

氖

苍喓

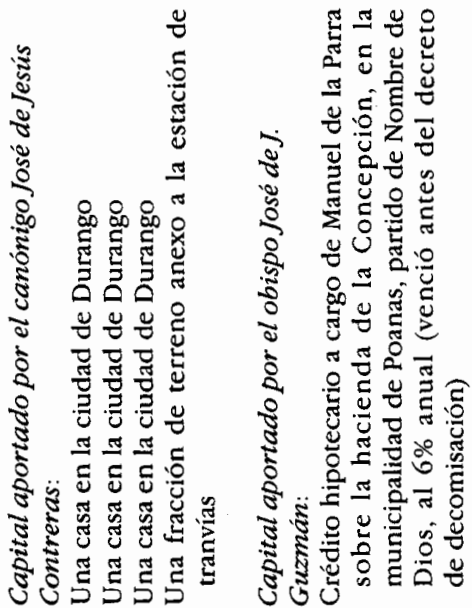

ธำ

융 娄

용

z듕 통

同贾

$\infty \stackrel{8}{0}$ 웡

践语

赔

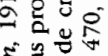

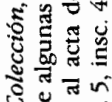

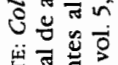

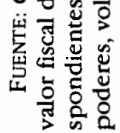


males y guarniciones. Su gerente y principal accionista, Miguel Verduzco, se fue a radicar a la ciudad de México, donde murió poco después. Los informes que se hicieron en la época carrancista sobre las causas de la intervención de esta compañía, esgrimían que ésta había gozado del favoritismo y los privilegios del gobierno de Porfirio Díaz y que Verduzco, ligado en negocios con el antiguo régimen y el clero, además de haber explotado en su beneficio la posición política que tenía, había impedido que otras empresas similares, que pretendían introducir el sistema eléctrico, pudieran aprovechar el negocio en condiciones favorables para los habitantes de la ciudad de Durango. Además, sus socios y cuñados, los hermanos Pérez Gavilán, habían sido "miembros distinguidos" de la Defensa Social y enemigos acérrimos de la revolución. Pese a que Verduzco negó los cargos, y que después de su muerte los socios iniciaron los trámites para recuperar la compañía, sus bienes fueron puestos a disposición del Ayunta. miento. ${ }^{35}$

Los principales motivos por los que el gobernador Pastor Rouaix y las comandancias militares de ese periodo confiscaron diferentes propiedades fueron: la pertenencia de sus dueños a la Defensa Social y haber tomado las armas para defender "al usurpador Huerta". De acuerdo con los datos recabados por la Dirección de Bienes In-

${ }^{35}$ En 1917 Carranza ordenó que fuera desintervenida con todos los implementos útiles, enseres, semovientes y edificios que le pertenecían. AGN, Periodo revolucionario, vol. 188, exp. 40. tervenidos en 1919 -con el objeto de llevar a cabo las desintervenciones respectivas-, los bienes confiscados comprendían, desde la época de Rouaix, 24 casas en la ciudad de Durango pertenecientes a las señoritas Carmen y María Luisa Veyán y Natera, "porque sus hermanos Rodolfo y Luciano tomaron las armas en favor de Huerta"; la Fábrica de Harina El Porvenir, propiedad de la Compañía Harinera de Durango, S. A., debido a que su principal accionista y gerente, el licenciado Francisco Gómez Palacio, "fue miembro prominente y organizador de la Defensa Social", y otra casa de su propiedad en la calle de Victoria que fue ocupada por las distintas fuerzas militares que estuvieron en Durango; ${ }^{36}$ la hacienda de La Ochoa, ubicada en la municipalidad de Poanas, partido de Nombre de Dios y una casa en la calle de la Constitución, propiedades estas últimas de Julio Bracho, porque "fue organizador y presidente de la Defensa Social"; la casa de comercio de Miguel Verduzco, conocida como la Francia Marítima, la cual refaccionaba de mercancías y dinero en efectivo a los agricultores y que fue completamente saqueada durante la ocupación de la ciudad, y la Compa-

${ }^{36}$ Esta casa estuvo ocupada de marzo a septiembre de 1914 por la Oficina de la Jefatura de Hacienda; de octubre de 1914 a agosto de 1915, por las fuerzas de la División del Norte villista; de septiembre de 1915 a mayo de 1916, por las fuerzas de la División de Durango de Domingo Arrieta; de junio a julio de 1916 , por fuerzas del general Maycotte; de agosto a noviembre de 1916, por fuerzas del general Gavjra; de diciembre de 1916 a junio de 1917 , sirvió como oficinas generales de la $5 a$. Brigada de Infantería. AGN, Bienes intervenidos, caja $5 \mathrm{E}$, exp. 9 . 
ñía de Tranvías de Durango, de la cual, como ya apuntábamos, era gerente y accionista el mismo Verduzco, quien fue acusado de tener "pésimos antecedentes políticos"; unas fincas urbanas y la hacienda de Tapias de Juan Gurrola, por haber sido organizador del cuerpo de Defensa Social, "defendiendo a Huerta con las armas en la mano". ${ }^{37}$

Rouaix había empezado a socavar de alguna manera el poder alcanzado por la elite durangueña $y$, a través de una serie de disposiciones, también acabó con los "tejemanejes" efectuados por algunos funcionarios del antiguo régimen, como fue la anulación de un contrato de compra que había hecho el gobernador porfirista Esteban Fernández de una casa donde se encontraba la Compañía Durangueña de Tabaco sin la aprobación de la legislatura y "en fraude de los intereses del estado". Esta casa supuestamente iba a ser destinada a los Montepíos, lo cual nunca se llevó a cabo. Por otro lado, Rouaix ordenó tomar posesión de las oficinas de los bancos establecidos en la ciudad de Durango, suspendiendo el cobro de los créditos pertenecientes a dichas instituciones y liberando a los deudores de la obligación de pagarlos hasta que, conforme a la ley, se procediera a la liquidación de los mismos. 38

Evidentemente, el primer régimen de la revolución constitucionalista en manos de Pastor Rouaix estuvo legitimado por el poder y el apoyo que le otorgaron los protagonistas de la lu-

${ }^{37}$ AGN, Periodo revolucionario, caja 191, exp. 5.

${ }^{38}$ Colección, 1917, pp. 46 y 57. cha armada en la entidad, lo cual le permitió dictar y llevar a la práctica una serie de disposiciones, muchas de ellas, las primeras en su género. Controlado el estado, las reformas se habían encaminado a enderezar la economía y a someter a los enemigos de la revolución, minando de alguna manera su poder y privilegios.

A un año de iniciado su gobierno, cuando se empezaban a ver resultados de su gestión, Rouaix se vio amenazado por los conflictos que surgieron con el comandante militar Domingo Arrieta, quien en el mes de agosto de 1914 puso al descubierto sus intenciones de asumir no sólo el control militar del estado, sino también el político. Ante la presión de Arrieta y su pretendida injerencia en los asuntos políticos de la entidad, las relaciones entre los dos mandos terminaron por deteriorarse $y$, finalmente, Rouaix fue obligado por aquél a renunciar al gobierno provisional de Durango.

Cuando se escindió la revolución a nivel nacional, el control político y militar de la entidad quedó en juego y ésta muy pronto se convirtió en escenario de las crecientes disputas surgidas entre las principales fuerzas beligerantes durangueñas: las del occidente serrano, acaudilladas por los hermanos Arrieta, y las de la región de los valles, dirigidas, entre otros, por Severino Ceniceros y Calixto Contreras. La lucha que se venía dando entre estas fuerzas por el control estatal quedó bien definida cuando en el plano nacional se dio la ruptura entre las grandes facciones revolucionarias: los Arrieta reconocieron a Carranza; Contreras y Ceniceros a Villa. El gobernador Rouaix, presionado 
por los primeros, renunció al cargo y, a pesar de los intentos de Villa por atraerlo al movimiento, prefirió seguir al "Primer Jefe" a la ciudad de México, en donde sería uno de sus principales colaboradores.

Después de la escisión revolucionaria, durante el escaso mes y medio que Domingo Arrieta logró ocupar la gubernatura estatal y su hermano Mariano la jefatura de armas, los jefes militares que encabezaban las fuerzas arrietistas desataron una verdadera "cacería de brujas" contra "los enemigos más acérrimos de la causa constitucionalista", a fin de que la oficina de Hacienda confiscara bienes y propiedades de los "traidores que pertenecieron a la Defensa Social". ${ }^{39}$ La mayoría de las denuncias que llegaron a dicha oficina no se concretaron, debido a que muy pronto el villismo controlaría el estado.

El Villismo en DuRango. "CoNTra LOS PODEROSOS DE OTRAS ÉPOCAS" (SEPTIEMBRE DE 1914 A OCTUBRE DE 1915)

Debido a la base militar con que contó el villismo en gran parte de la entidad durangueña, la capital les fue arrebatada a los Arrieta y el estado se convirtió durante más de un año en un enclave de la zona controlada por Villa, quien dejó la administración en manos de los dirigentes locales. En este periodo ocuparon la gubernatura Severino Ceniceros y Jesús Díaz Couder por un corto tiempo, así como Emiliano G. Saravia y Máximo García, cuyos

${ }^{39}$ AGN, Bienes intervenidos, vol. 5E, exp. 12. gobiernos destacaron por tratar de beneficiar a la población más necesitada.

Desde los tiempos de Rouaix y durante los gobiernos villistas, Durango permaneció en una siuación de relativa tranquilidad política y militar, gracias a que los grandes hechos de armas se desarrollaron fuera del estado. Pero mientras no se definiera el triunfo de Villa en los campos de batalla, era necesario cooperar en el sostenimiento de sus ejércitos y, a la vez, poner mayor atención a las necesidades más apremiantes de la población y tratar de solucionar la precaria situación económica que existía, sobre todo en el campo, que había sido arrasado desde los primeros años de lucha y que, pese a los esfuerzos de Rouaix, no se había podido recuperar. Por otra parte, durante este periodo el poder de la mayoría de los hacendados y de la elite económica durangueña fue cada vez más quebrantado, y muchos de sus integrantes que aún permanecían en la entidad, terminaron por ser expulsados o salir huyendo.

Pese a todo, a principios de $1915 \mathrm{la}$ situación económica de Durango continuaba en dificultades por el aumento de la carestía y la escasez de granos. Para dar solución prioritaria a este problema, el gobernador villista, el abogado Emiliano G. Saravia, que paradójicamente pertenecía a una de las familias más prominentes de Durango -y quien rompiendo con su condición de clase y gracias a sus simpatías hacia Villa y sus buenas relaciones con los principales caudillos durangueños, su familia no sufrió persecuciones-, organizó una Sociedad Cooperativa Proveedora de Maíz, a través de la cual el gobier- 
no compró grandes cantidades de grano y las vendió a muy bajo costo entre las familias más pobres, mientras se hicieran las próximas cosechas. Los comerciantes, incluyendo los propietarios de haciendas y los extranjeros, se vieron obligados a contribuir con préstamos a la cooperativa, formando un capital de cerca de 200000 pesos. ${ }^{40}$ Además, Saravia fijó los precios de los principales artículos de primera necesidad ${ }^{41}$ y trató por todos los medios de aumentar la producción de las cosechas para resolver las dificultades de abastecimiento en que se encontraba la entidad. Para ello, puso especial atención en que se intensificaran los trabajos de siembra en las haciendas intervenidas por el gobierno y ofreció proporcionar tierras a todos aquellos que las solicitaran. ${ }^{42}$ Una buena parte de los ingresos derivados de la explotación de las haciendas confiscadas fue utilizada para financiar la lucha del villismo que se desarrollaba fuera del estado.

Durante la permanencia de Saravia en el gobierno, se dieron los primeros pasos con respecto a la entrega de las tierras solicitadas por algunos pueblos, como sucedió con la Sociedad Proletaria de Avilés que, después de su petición, logró que se iniciara el levantamiento del plano que ocupaba la población de Avilés y sus alrededores por conducto de la recién creada Direc-

\footnotetext{
${ }^{40}$ National Archives Washingon (en adelante NAw), Records of the Departament of State relating to internal Affairs of Mexico, 1910-1929 (Microfilms, Biblioteca "Daniel Cosío Villegas" del Colegio de México), rollo 45, doc. 15196.

${ }^{41}$ Periódico Oficial, 16 de mayo de 1915.

${ }^{42}$ La Voz de la Revolución, 26 de marzo y 11 de junio de 1915.
}

ción General de Agricultura. Sin embargo, parece ser que como los generales villistas Máximo y Benito García ocupaban dicha hacienda, ${ }^{43}$ el estudio no prosperó. También, en relación con los conflictos por tierras que se habían suscitado años atrás entre la hacienda de Santa Catalina del Álamo y los habitantes de Peñón Blanco, en el partido de Cuencamé, organizados como "Sociedad de condueños", Saravia había reconocido a estos últimos toda sus propiedades, o sea 24 y medio sitios de ganado mayor, "los que gozarían en común mientras se hiciera el fraccionamiento definitivo". ${ }^{4}$

Durante este tiempo, las confiscaciones se siguieron haciendo por las mismas causas de abandono, o porque sus dueños eran enemigos de la revolución. Algunas de las haciendas que ya estaban ocupadas, sólo cambiaron de administrador. Otras fueron intervenidas por órdenes expresas del general Villa y muchos de sus subalternos tomaron posesión de ellas o las administraron directamente, lo cual no sólo significó un mayor debilitamiento de la oligarquía terrateniente del estado, sino que proporcionó trabajo a los campesinos. Los administradores civiles o militares de las haciendas intervenidas, nombrados por el gobierno villista o por los jefes de armas, reemplazaron a los propietarios, arrendando o dando en aparcería los terrenos laborables. En algunos casos los antiguos administradores permanecieron en sus puestos y

\footnotetext{
${ }^{43}$ CONDUmex, archivo Carranza, fondo $\mathrm{xx}$, carpeta 56, f. 6329.

${ }^{44}$ AGA, Terrenos nacionales. Ejidos 1.24(07), exp. 34, leg. 2.
} 
respetaron los contratos de arrendamiento ya existentes; en otros, fueron removidos, quedando la administración bajo el control directo de dirigentes revolucionarios locales.

Si bien las haciendas ocupadas por el villismo estaban ubicadas en distintas partes de la entidad, hubo una marcada concentración de confiscaciones en La Laguna, importante región algodonera que Villa controlaba directamente. Además del tipo de producción, esta comarca tenía una posición estratégica por su comunicación ferroviaria directa con la Agencia Financiera del Ejército del Norte, en Ciudad Juárez, para vender algodón en Estados Unidos.

Las confiscaciones villistas fueron más vigiladas en La Laguna que en el resto del estado. Por disposiciones del propio Villa, con el fin de reorganizar y activar los trabajos agrícolas, las haciendas intervenidas estuvieron administradas por la Oficina Militar del Algodón Decomisado, que dependía directamente de la Comandancia Militar de la comarca lagunera y por la Comisión de Agricultura de La Laguna, perteneciente a la Oficina de Hacienda y creada ex profeso por Villa para fomentar la agricultura en esa región.

La Comandancia Militar ordenó que fueran explotados los ranchos abandonados de la zona y que se repartieran tierras en aparcería o renta de las fincas, intervenidas militarmente porque sus dueños $o$ arrendatarios "tuvieron motivos políticos del tiempo del huertismo". Según el informe que la Comisión de Agricultura en La Laguna rindió a Carranza en octubre de 1915, cuando el villismo ya había sido prácticamente derrotado, durante los meses precedentes los términos de los contratos de concesión de estas fincas se habían ajustado a los usos y costumbres locales, por un tiempo específico relacionado con el ciclo agrícola y sujetos a renovación. ${ }^{45} \mathrm{El}$ sistema de vigilancia de los ranchos administrados militarmente se hacía a través de inspectores e interventores que semanalmente rendían un informe sobre la pizca y despepite de algodón a la Comisión de Agricultura.

Entre las fincas rústicas "secuestradas" por el villismo en La Laguna, dentro del territorio durangueño, en el partido de Mapimí estaban La Loma, -Avilés, San Carlos, San José, El Compás, San Felipe, Carrizal, Buena Vista, San Gonzalo, La Reforma, Jauja y Anexas, Chihuahuita, San Alberto y Huitrón, Santa Rosa, Las Huertas, Leocadias y San Sebastián, cuyos propietarios eran, en gran parte, capitalistas emparentados con la elite de Chihuahua, como los Terrazas, Los Zuloaga y los Luján y sus administradores, en su mayoría extranjeros. Casi todas estaban arrendadas y, según los distintos contratos de aparcería, los pagos al gobierno oscilaban entre 15 y $35 \%$ de las cosechas levantadas. ${ }^{46}$ Por citar algunos ejemplos, Santa Rosa estaba rentada al francés Miguel Bernardini, quien la había recibido con toda su maquinaria, útiles de labranza, fincas y muebles por

45 "Comisión de Agricultura de La Laguna, Informe rendido al señor general Venustiano Carranza, primer jefe del ejército constitucionalista, encargado del poder ejecutivo de la nación", Torreón, Coah., 24 de octubre de 1915, CONDUMEX, archivo Carranza, fondo XX1, carpeta 56.

${ }^{46}$ Ibid., y AGN, Periodo revolucionario, vol. 187 , exp. 57, 1917. 
un plazo de cinco años, al 33\% de los productos líquidos. Cuando Villa controló la zona, Bernardini se vio obligado a entregar a la comisión respectiva dicho porcentaje que por concepto de rentas correspondía al dueño, que era José Ma. Luján. Los ranchos Leocadias y Huertas tenían una parte repartida entre aparceros pobres que sembraban trigo y maíz y que daban dos lotes y medio de algodón a un parcionero que debía pagar el $15 \%$ de los frutos. San Sebastián estaba sembrado de trigo y maíz por parcioneros pobres. En El Compás, los parcioneros debían pagar el $30 \%$ de los frutos en el cultivo de cinco lotes de algodón. Chihuahuita estaba arrendada por 16500 pesos a un español que continuó con el contrato, pero con la obligación de pagar la renta al gobierno. ${ }^{47}$ Las rentas y productos eran entregados a la Comisión de Agricultura y a la Oficina Militar del Algodón Decomisado. Estas fincas se conservaron como unidades productivas y las confiscaciones se hicieron en función de las necesidades económicas del villismo.

Con el dominio de la región lagunera, Villa pudo controlar en gran medida la producción, el tráfico y la venta del algodón, parte del cual se manufacturaba en las principales fábricas de hilados y tejidos que, a su vez, aquél tenía intervenidas, como La Amistad y La Victoria, en Gómez Palacio, y La Fe, en Torreón, las cuales trabajaron bajo las órdenes de la Comandancia Militar. ${ }^{48}$ También la famosa Compañía Industrial Jabonera de La Laguna, propiedad del estadu-

47 "Comisión", condumex, loc. cit. ${ }^{48}$ Ibid. nidense Juan Brittingham, ubicada en Gómez Palacio, que procesaba la semilla de algodón, fue ocupada por Villa en varias ocasiones y, según las urgencias de la guerra, éste le impuso préstamos forzosos y le incautó grandes partidas de jabón para sus tropas. ${ }^{49}$

Mientras no se definió la lucha militar, La Laguna en poder de Villa representó una fuente muy poderosa de ingresos. Por lo pronto, era necesario tener en producción las ricas haciendas algodoneras, situadas cerca del nudo ferroviario más importante del norte del país.

Durante el control villista en La Laguna, muchas casas y comercios intervenidos en Gómez Palacio y Torreón continuaron rentados, ocupados por el nuevo gobierno o usados como cuarteles por las fuerzas militares. Otras se confiscaron durante este periodo y pertenecieron a la Oficina de Confiscaciones de fincas urbanas, que a su vez dependía de la de Bienes Intervenidos y Reclamaciones. Cuando los carrancistas recuperaron el control de la región, se creó la Comisión Interventora de Decomisaciones de La Laguna, que se ocupó de administrar estas fincas, tanto rústicas como urbanas.

En otras zonas del estado, la mayoría de las fincas rurales y urbanas ocupadas durante el periodo villista fueron administradas directamente por la Oficina de Bienes Intervenidos y Reclamaciones que recaudó el producto del arrendamiento, tanto a civiles como a militares. El destino final de una gran parte de las ganancias obtenidas a trap. 84. 


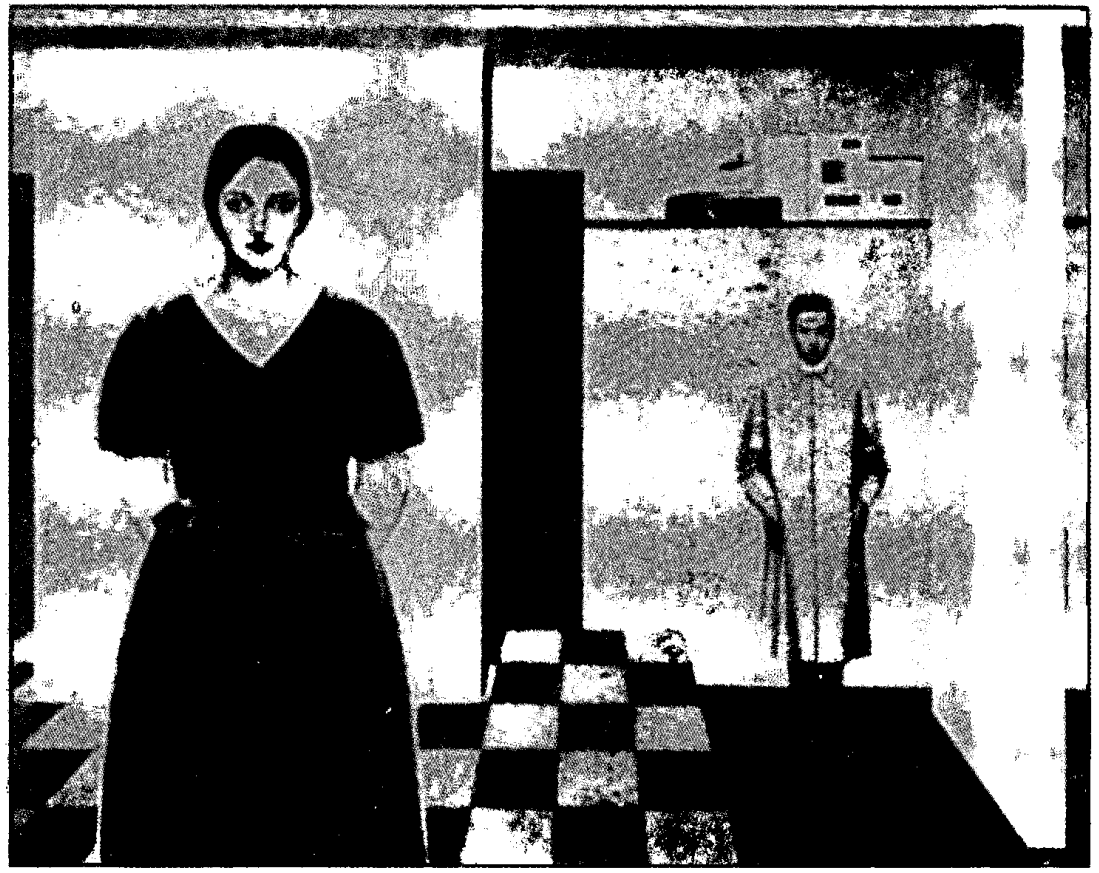

vés de las confiscaciones fue la Agencia Comercial y Financiera de la División del Norte, en Chihuahua y, como afirma Katz, estos ingresos contribuyeron a poner en pie, con la compra masiva de armas en Estados Unidos y el pago de un buen sueldo a los soldados, al ejército revolucionario mejor pertrechado y más poderoso de la revolución. ${ }^{50}$

De las grandes haciendas confiscadas, varias estuvieron en poder de los generales más cercanos a Villa. Entre ellas destacaron algunas estancias per-

${ }^{50}$ Katz, "Pancho", 1985, p. 100. tenecientes a la hacienda de Santa Catalina del Álamo, en el partido de Cuencamé, intervenidas por órdenes del mismo villa y administradas por los hombres de la brigada de Calixto Contreras; ${ }^{51}$ la de Tapona, anexa a Juan Pérez, también explotada por hombres de Contreras; ${ }^{52}$ la de Avilés, en el partido de Mapimí, ocupada por los hermanos Benito y Máximo García; ${ }^{53}$ la hacienda de San Ignacio, anexa a la de San Isi-

\footnotetext{
${ }^{51}$ Walker, "Y hay que quedar", 1996.

52 INAH, 4a. serie Xerografía, leg. 201, doc. 6.

53 "Comisión", CONDUMEX, loc. cit.
} 
dro en Chihuahua, propiedad de Juan Terrazas, situada en el partido de Indé, estuvo administrada directamente por Tomás Urbina, lo mismo que las Nieves, anexa de Canutillo, en el mismo partido, donde este general mantuvo su dominio prácticamente aislado del resto de la entidad, según las ya muy conocidas descripciones de John Reed sobre la forma como Urbina vivía y administraba a su antojo su pequeño feudo. ${ }^{54}$

Según las evidencias documentales, otras fincas rústicas de menor importancia fueron encargadas a oficiales villistas, como fue el caso de la hacienda de Alisos y el rancho del Trébol, en la municipalidad de Canatlán, las cuales estuvieron administradas por el mayor Ponciano Ortega, quien a finales de 1914 recibía como sueldo 150 pesos mensuales y al año siguiente 300 pesos. Los salarios de los mayordomos, boyeros y mozos oscilaban entre 1.25 pesos y 25 centavos diarios. ${ }^{55}$ Alisos y El Trébol estuvieron rentadas en 4500 pesos por contratos de un año, pagaderos en bonos del estado y otros de circulación forzosa. Los arrendatarios recibían sólo las semillas necesarias para el sostenimiento de las haciendas durante el tiempo del contrato, y dejaban las restantes a disposición del gobierno en las mismas haciendas. Los bueyes, la mulada y demás animales de trabajo, así como los implementos agrícolas, eran entregados por "riguroso inventario" y, al término del contrato, se devolvían al gobierno, con la salvedad de que si por falta de garan-

\footnotetext{
54 Reed, México, 1971.

55 Un escribiente y una profesora ganaban 75 pesos mensuales. AHGED, caja 205, 1913-1915.
}

tías no se podían conservar las cosas, los arrendatarios no se obligaban a reponer animales robados. El maíz, trigo y otras semillas que ya estaban sembrados seguirían por cuenta de los arrendatarios, quienes tenían que respetar cualquier arreglo hecho de antemano con medieros y otra clase de parcione. ros. El ganado tenía que ser conservado con el mayor cuidado posible y los que ocupaban la finca no se hacían responsables de ninguna clase de pérdidas debidas a casos fortuitos, herrando la mitad con sus fierros y dejando el resto a disposición del gobierno. Asimismo, los arrendatarios se comprometían a repartir la mayor cantidad de tierras a parcioneros y a proporcionar trabajo para el sostenimiento de la gente de las haciendas. ${ }^{56}$

Otras fincas, como las de San Antonio de Menores y Palmitos, en el partido de San Juan del Río, estaban administradas por un oficial villista, que en un principio no percibía sueldo. En este mismo partido estuvieron intervenidas Güichapa ${ }^{57}$ y Corralejo, en las

\footnotetext{
${ }^{56}$ Contrato que la Dirección General de Agricultura en representación del Gobierno del Estado de Durango, celebra con los señores Campa Hermanos para el arrendamiento de la hacienda de Alisos y El Trébol, pertenecientes al mismo estado, municipalidad de Canatlán, partido de la capital, Durango, 10 de abril de 1915, en ibid.

${ }^{57}$ La hacienda de Güichapa estaba arrendada por el cónsul estadunidense Hommer $C$. Coen, quien protestó ante el gobernador por "tan injustificada acción". Parece ser que, a pesar de que Villa fue informado de las protestas del cónsul, la hacienda permaneció confiscada. NAW, Records of the Department of State relating to internal Affairs of Mexico, rollo 45, doc. 15196.
} 
que un capitán fue comisionado para repartir las tierras entre terciarios; San Bartolo, en el de San Juan de Guadalupe; Santa Lucía, en el de Durango; San Marcos, en el de Cuencamé; La Ochoa, en el de Nombre de Dios, la cual fue dada en arrendamiento a varios parcioneros; las haciendas de El Mortero y La Luz, en el mismo partido, en las que el administrador de la primera recibía 60 pesos mensuales, mientras que al de la segunda se le daba, como retribución por sus servicios, la cuarta parte de la cosecha. ${ }^{58}$

Por este tiempo continuaron las persecuciones y confiscaciones contra miembros de la antigua elite. Según publicó la prensa de la época, "los ricos hacendados Felipe y Luciano López fueron expulsados", y Antonio Bracho fue aprehendido porque, al tener conocimiento de que se le iba a decomisar su maquinaria para tejidos, pagó a un mecánico para que la descompusiera, ${ }^{59}$ además, algunos negocios fueron intervenidos, como la Cía. Maderera de la Sierra de Durango, que tenía como principales accionistas a los López Negrete, junto con varios extranjeros. En este caso, de acuerdo con la política del villismo, se hizo un convenio con el Consulado estadunidense, con el fin de que fuera nombrado un interventor que representara los intereses extranjeros para que éstos no fueran lesionados. También por este tiempo fueron intervenidas las fábricas de sodas San Francisco y La Estrella, la primera perteneciente a Antonio Bra-

${ }^{58}$ AHGED, caja 205, 1913-1915.

${ }^{59}$ La Voz de la Revolución, 19 de marzo de 1915. cho, así como los Baños del Fuerte. ${ }^{60}$ Según carta del cónsul de México en Los Ángeles para pedir ayuda a Carranza para la familia Martos de Durango, esta familia sufría "los horrores de Villa y Urbina", quienes habían mandado fusilar a varios de sus miembros y confiscado tres haciendas y tres minas. ${ }^{61}$

$\mathrm{Si}$ bien continuaron las intervenciones, desde esta época empezaron las solicitudes para recuperar propiedades confiscadas, pero para ello, los solicitantes tenían que demostrar al general en jefe de la División del Norte su neutralidad "en los acontecimientos políticos del país". ${ }^{62}$

Al final del dominio villista, se hallaban confiscadas en la ciudad de Durango alrededor de 30 casas, de las cuales, la mayoría las rentaba el gobierno a particulares; algunas de ellas, por diversas causas, no pagaban renta, ${ }^{63}$ y otras

${ }^{60}$ Ibid., 19 de febrero de 1915 y 24 de marzo de 1915 .

${ }^{61}$ CONDUMEX, archivo Carranza, fondo XXI, $f$. 5813. Podría tratarse de Joaquín Martos, dueño de la hacienda de Cruces, en el partido de Indé.

62 AHGED, caja 205, 1913-1915. No he encontrado evidencias de que se haya devuelto ninguna propiedad durante este periodo.

${ }^{63}$ De las quince casas confiscadas a Genoveva Curbelo, viuda de Rodríguez, dos eran cuarteles y otras estaban ocupadas sin orden por militares, dos eran escuelas y no pagaban renta, había una tienda y un salón cantina; de las tres casas confiscadas al licenciado Juan Santa Marina, una era cuartel y no pagaba renta. Una casa "muy grande y elegante" perteneciente al licenciado Manuel Bermúdez que estaba rentada; una casa de E. C. de Villalva, que no pagaba la renta por ser oficina de Telégrafos; dos casas de Carlos Bracho, una desocupada y otra que no paga renta; los altos de la casa de Miguel Verduzco, que no pagaba renta, y los bajos donde se encontraba la tienda Lombard Hnos., que pagaba renta; la casa de Julián Medina, que no 
no estaban registradas en los libros de la Oficina de Bienes Intervenidos y Reclamaciones y las tenían "intervenidas de motu proprio" algunos militares. Entre las propiedades controladas por esa oficina se encontraba la casa del Banco de Londres y México que ocupaba, sin pagar renta alguna, el súbdito inglés Germán French, quien manifestó que la tenía "por orden de don Calixto Contreras". También había muebles confiscados por los villistas, los cuales fueron recogidos, quedando a disposición de la nueva Jefatura de Operaciones. ${ }^{64}$

En relación con las disposiciones confiscatorias, si bien Villa permitió que sus dirigentes locales actuaran en sus respectivas zonas con un alto grado de independencia, en la ciudad de Durango demostró una actitud especialmente hostil hacia algunos miembros de la elite y actuó personalmente contra ellos. Cuando los hermanos Arrieta trataron de tomar la capital en agosto de 1915, el mismo general Villa acudió a combatirlos y, una vez que

pagaba renta por estar ocupada por el Estado Mayor del general Murguía; la casa de Ángela Flores, que no pagaba renta por estar ocupada por el general Murguía; la casa de Tomás de la Parra, que no se había cobrado por vivir en ella el coronel Saracho; casas pertenecientes al clero, como eran el Arzobispado, en el que existía un colegio, una escuela oficial, que no pagaba renta y en la que el director rentaba habitaciones; el Seminario, en el que había una escuela de niños y no pagaba renta; la Escuela Superior de Niñas que tampoco pagaba renta. También se registró el crédito hipotecario de los De la Parra, que no habían pagado los intereses vencidos, en espera de la resolución del gobierno al pedir condonación. Ibid.

${ }^{64}$ Ibid. recuperó la plaza, según el relato del villista Vargas Arreola y otras evidencias documentales, el "Centauro" aprovechó su estancia en esa ciudad para "ajustar cuentas con los poderosos de otras épocas". Procedió con mano de hierro contra los ricos de la región, haciendo prisioneros a renombrados miembros de la elite con apellidos muy conocidos, como Bracho, Gómez Palacio, Gurza, Pérez Gavilán, Paura y De la Parra, entre otros, a quienes se llevó consigo a Torreón, con destino a Chihuahua. Gracias a la intervención de familiares del gobernador Saravia, la mayoría fueron puestos en libertad después de pagar por su rescate. Entre los tres que llegaron a Chihuahua y fueron fusilados por órdenes de Villa, se encontraba Antonio Bracho, hacia cuya familia iban dirigidas "las iras del general Villa, por el papel de caciques que habían representado durante la dictadura porfiriana y por su ensañamiento con los pobres". ${ }^{65}$ Para la elite durangueña

esos atentados que cometió Villa contra varias personas prominentes tuvieron funestos resultados; después de un verdadero y prolongado calvario de maltratos, privaciones, sufrimientos y exacciones que los hizo sufrir en esta ciudad, en Torreón y en Chihuahua y todas las poblaciones de tránsito, los asesinó en la última en un momento de furor de sangre que le vino [...] Bien sabido es que los elementos insanos de la revolución, que los hay a millares, han tenido como piedra angular de su idea a los ricos, y contra ellos han dirigido sus principales ataques destruyén-

${ }^{65}$ Vargas, Sangre, 1988, pp. 268-270. 
dolos a ellos, después de destruir sus intereses. ${ }^{66}$

Antes de salir de la capital, Villa nombró como gobernador y comandante militar del estado al general Máximo García, quien gobernó durante los meses más difíciles del villismo, que ya se encontraba en derrota.

Los gobiernos villistas de Durango tendieron a nivelar la economía estatal, pero sobre todo se propusieron mejorar las condiciones económicas de las clases más desposeídas. Sin embargo, debido a su reducida vigencia, pocas cosas se pudieron consolidar, sobre todo por la atención que requería la lucha militar librada fuera del estado.

En la estructura agraria, si bien no se obtuvieron cambios radicales, se logró eliminar por un tiempo el poder económico de los grandes hacendados y se proporcionó trabajo a un buen número de campesinos, mejorando sus condiciones de trabajo. En este sentido, el gobernador Máximo García decretó el aumento a 1.50 pesos del salario que disfrutaban los peones de las haciendas, que por haber sido confiscadas estaban bajo su control, y considerando que tal beneficio no" debería ser exclusivo para los servidores del gobierno villista, sino que debía extenderse a todas las clases rurales, decretó que el jornal máximo para los peones ocupados en las labores del campo fuera de un peso, cuando en algunos lugares se seguían pagando de 18 a 50 centavos. Asimismo, dispuso que los

66 Archivo del Supremo Tribunal de Justicia de Durango (en adelante ASTJD), caja 117, 1919. empleados y sirvientes de las fincas tuvieran un aumento de $25 \%$ sobre los sueldos que disfrutaban. ${ }^{67}$ Pese a que estas medidas apenas se pudieron aplicar por la inminente derrota del villismo en la entidad, la población rural había notado cambios, sobre todo al presenciar la expulsión de los hacendados, quienes por lo pronto habían dejado de poseer sus tierras y haciendas. Si bien las represalias contra muchos terratenientes se concretaron a las ocupaciones y confiscaciones de bienes, ello no representó, sin embargo, una transformación de las estructuras agrarias existentes. Las relaciones laborales apenas se modificaron, pese a que grupos agraristas continuaron ocupando las tierras tomadas desde el inicio de la lucha armada; poco después de la derrota del villismo en el estado, éstas serían formalmente devueltas a sus antiguos dueños.

El gobierno de Máximo García cayó en octubre de 1915, cuando la capital del estado fue recuperada definitivamente por el ejército carrancista. A pesar de los continuos esfuerzos de los hermanos Arrieta por recuperar Durango, éstos no tuvieron ni la fuerza ni el apoyo suficientes para hacerlo, por lo que el villismo duranguense fue derrotado por generales enviados por Carran$\mathrm{za}$, ajenos a Durango, quienes competirían con los Arrieta por el dominio estatal. Pese a ello, por disposiciones de Carranza, Mariano Arrieta ocupó la gubernatura, pero sólo de noviembre de 1915 a enero de 1916. Después se inició la etapa conocida como preconsti-

${ }^{67}$ Periódico Oficial, 10 de octubre de 1915. 
tucional, que en Durango duró casi 18 meses, y en la cual estuvieron al frente del gobierno los generales carrancistas Arnulfo González, Fortunato Maycotte, Gabriel Gavira y Carlos Osuna y, por un tiempo, la Comandancia Militar del general Francisco Murguía; todos ellos gobernaron de una manera semiautónoma del mando carrancista.

\section{CARRANCISTAS PROPIOS Y EXTRAÑOS. LOS NEGOCIOS AMPARADOS POR LA REVOLUCIÓN (ENERO DE 1916 A AGOSTO DE 1917)}

Los generales Murguía y González llegaron a Durango con la intención de mantener su poderío político dentro del sector militar, por lo que provocaron conflictos con los hermanos Arrieta, al lanzar una serie de denuncias contra ellos, que pusieron en evidencia los negocios turbios que estos durangueños estaban haciendo al amparo de la revolución. Murguía, de quien más tarde también se descubrirían sus jugosas ganancias con el guayule, acusaba en estos momentos a Mariano Arrieta de haber dispuesto del dinero de la Secretaría de Guerra para provecho personal y para sus negocios mineros en Topia y San Andrés de la Sierra, ${ }^{68}$ imputación que no era improbable, ya que Arrieta por este tiempo se dedica-

${ }^{68}$ Archivo de la Secretaría de la Defensa Nacional (en adelante ASDN), ramo Cancelados, exp. XI/111/2-1202, f. 94 . En 1919 continuaba el proceso por malversación de fondos y en febrero de 1921 se declaró no haber lugar a dictar orden de proceder en la averiguación previa. ba a fundir barras de oro y plata en la Casa Maldonado and Co. ${ }^{69}$

Domingo Arrieta también fue inculpado de fraude a la nación en virtud de haber efectuado fletes de sal y harina con transportes militares, cobrando por ello una cantidad considerable. Aunque el general declaró que los efectos transportados habían sido entregados a comerciantes de esa ciudad en pago de vestuario para la División de Durango que él comandaba, el juicio continuó hasta que Carranza dio instrucciones a la Secretaría de Guerra en el sentido de suspender el procedimiento, manifestando que los fletes los cubriría la nación al director de los Ferrocarriles Nacionales. ${ }^{70}$

El control del poder militar abrió paso a numerosos jefes y comandantes para hacer substanciosos negocios o llevar a cabo prácticas usureras. A lo largo de la lucha, muchos de ellos también se enriquecieron disponiendo libremente del sueldo y el abastecimiento de sus tropas, o declarando números elevados de hombres en las listas de control que presentaban a sus superiores. Desde los tiempos de Rouaix existen evidencias de que Domingo Arrieta explotaba el abasto de carnes en la ciudad de Durango y de que, según informes del mismo Rouaix, él y su hermano Mariano solicitaban 2000 y 4000 pesos diarios, sin que ni uno ni otro dieran cuenta del efectivo de tro-

69 Archivo Histórico de la Secretaría de Relaciones Exteriores (en adelante AHSRE), L-E 819 R, leg. 3(2), f. 155.

70 ASDN, ramo Cancelados, exp. XI/111/1308, f. 339. 


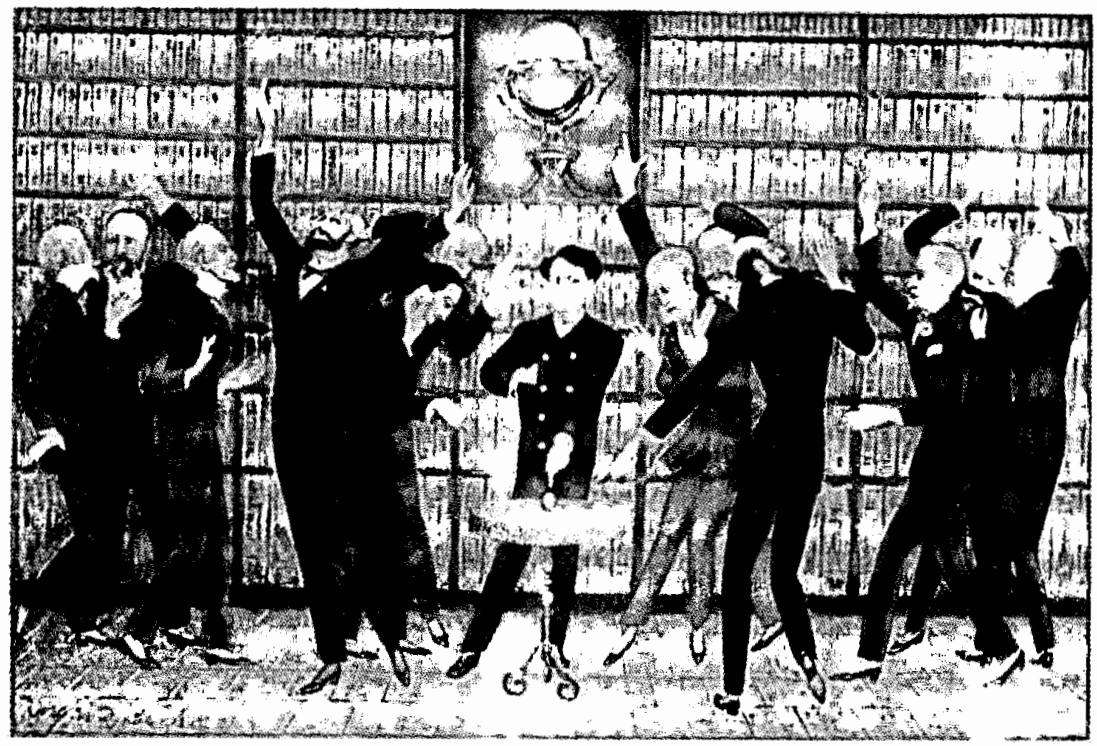

pas. ${ }^{71}$ Al triunfo del carrancismo en la entidad, cuando los Arrieta tuvieron por un tiempo el control político y militar, otorgaron concesiones a familiares y amigos. En diciembre de 1915 se registró un faltante considerable en la Dirección General de Rentas, en el que se incluían varios recibos firmados por el secretario interino de Domingo Arrieta. ${ }^{72}$ Asimismo concedieron la ocupación gratuita de casas para ser habitadas por particulares o entregadas a algunos generales, jefes de brigada y del Estado Mayor, como sucedió con

${ }^{71}$ Rouaix a C. Contreras, 18 de noviembre de 1913, AHGED, Libro copiador del gobernador Pastor Rouaix.

${ }^{72}$ Ibid., caja 205, 1913-1915. el coronel Francisco Arrieta, quien por autorización del gobernador interino Mariano Arrieta dejó de pagar la renta de una casa confiscada, de acuerdo con las anotaciones correspondientes en los libros de la Oficina de Bienes Intervenidos. ${ }^{73}$ Fuera de estos casos "especiales" que denotaban a todas luces los favoritismos otorgados por la autoridad en turno, las disposiciones de la nueva administración carrancista con respecto al pago de impuestos o rentas atrasadas sobre fincas intervenidas fueron más drásticas, ya que a aquellos que no pagaron la renta se les exigió la inmediata desocupación de las fincas, ${ }^{74}$ a

${ }^{73}$ Ibid.

${ }^{74}$ Ibid. 
diferencia de las llevadas a cabo durante el villismo, en el que, al tratarse de "inquilinos verdaderamente menesterosos", se les había concedido tiempo para pagar en pequeños abonos. ${ }^{75}$

Otro caso de abuso de autoridad adjudicado a Domingo Arrieta salió a la luz cuando éste ya era gobernador constitucional del estado. En noviembre de 1917 Arrieta fungió como fiador del comerciante Miguel R. Murúa, quien contrató en arrendamiento la hacienda de Santa Catalina del Álamo y Anexas, propiedad de la señora Bárbara Vincent, viuda de Martínez del Río, obligándose a recobrar todas las tierras que se encontraban "usurpadas por personas extrañas" en un plazo de dos años y medio y comprometiéndose a hacer que fueran reconocidos y respetados los derechos de los dueños conforme a sus títulos. Los arrendatarios dispondrían libremente de los pastos y de los productos espontáneos de la tierra, como lechuguilla, palma, maguey y candelilla, así como del uso limitado de la leña de los montes, excluyendo la planta del guayule, que estaba adjudicada por contrato desde 1915 al inglés Patrick O'Hea, administrador de una de las estancias de la hacienda. El costo del arrendamiento sería el importe de las contribuciones adeudadas por la finca, así como los gastos generales que se generaran. Ante el atraso del pago de dichas contribuciones, el gobernador Arrieta embargó a Murúa 351 toneladas de maíz, y con el producto de la venta de la semilla, el mismo gobierno se cobró 3984 pesos que se

${ }^{75} \mathrm{Ibid}$. adeudaban por concepto de contribuciones, apropiándose de una considerable cantidad a la que ascendía el sobrante. Si bien Murúa demandó al gobierno de Arrieta por el "sucio negocio" en que estaban envueltas "las personas que merced a sus altos puestos, hicieron desaparecer cerca de 400 toneladas de maiz", Arrieta fue favorecido por los funcionarios del juzgado y Murúa no recobró la cantidad demandada. $^{76}$

Con respecto a las confiscaciones, éstas continuaron durante los gobiernos carrancistas y las propiedades intervenidas se convirtieron cada vez más en fuente importante de enriquecimiento. Numerosas fincas sólo cambiaron de administrador y renovaron sus contratos de arrendamiento o aparcería y, en la mayoría de los casos, los jefes militares, en tránsito por el estado, aprovecharon sus rendimientos con más frecuencia que durante la dominación villista para emplearlas en su provecho personal. Surgieron los abusos y la indisciplina en el ejército como resultado, entre otras cosas, de la falta y el atraso del pago a las tropas, lo cual se reflejó en la turbia administración de algunas propiedades intervenidas y en las confiscaciones "no oficiales" de otras. En este sentido, se reportaban abusos y atropellos de los soldados, como los que guarnecían la hacienda de Tapona, o en San José de la Boca, en donde los pueblos aledaños se quejaban de la hostilidad de las tropas carrancistas que no respetaban nada y que habían

\footnotetext{
${ }^{76}$ Demanda ordinaria sobre rendición de cuentas con pago, ASTJD, caja 117, 1919
} 
expropiado casas por voluntad y a la fuerza. ${ }^{77}$

Por este tiempo, el villismo, convertido en un movimiento disperso de guerra de guerrillas, se mantuvo en actividad en Durango, y sus gavillas ocuparon $y$ controlaron en forma intermitente algunas haciendas que se encontraban en sus zonas de influencia, principalmente en los partidos de Cuencamé e Indé.

Durante el carrancismo, las fincas intervenidas desde tiempos de Rouaix fueron controladas por la Administración de Bienes Intervenidos, ahora bajo la jurisdicción de la Secretaría de Hacienda. Algunas se dieron en arrendamiento a condición de que fueran trabajadas, quedando muchas de ellas en manos de jefes militares.

Las formas de intervención habían variado poco en cada caso. En general, dentro de las haciendas las condiciones siguieron siendo casi las mismas de antes: a veces continuaron los administradores y campesinos trabajando como lo habían hecho hasta entonces, sin embargo, una buena parte de las ganancias y de la producción quedaba a disposición de los militares.

Aun cuando Carranza dispuso que los bienes confiscados fueran devueltos a una oficina central de Administración de Bienes Intervenidos, durante este tiempo continuaron las confiscaciones en el estado, algunas controladas por los dirigentes regionales y otras por el gobierno estatal. Tal fue el caso de la sucesión de Juan Nepomuceno Flores y de la señora Ángela Flo-

${ }^{77}$ AHSDN, ramo Histórico, exp. XI/481.5/111, fs. $113,141,217$. res, viuda de Flores que, "por estar comprobado que esta última fue grande enemiga de la revolución y prestó apoyo pecuniario tanto al reyismo en el estado, como al huertismo en la ciudad de México", sus bienes fueron intervenidos por órdenes de la Secretaría de Hacienda en octubre de 1916, bajo la advertencia de que, al tomar posesión de dichos bienes, en caso necesario se ayudará por medio de la fuerza pública para desalojar a los poseedores. Los bienes comprendían la hacienda de la Ferrería, con sus doce pertenencias, ${ }^{78}$ la hacienda de Guatimapé y Anexas y 19 fincas urbanas en la capital del estado, entre las que se encontraban el edificio conocido como "El Palomar" y el asilo Juan Nepomuceno Flores, que quedó destinado al mismo objeto. ${ }^{79}$

El procedimiento de confiscación en este caso, puede ilustrar los que se hicieron en esta época. Se nombraba un interventor especial que tomaba posesión de los bienes y se encargaba de hacer un minucioso inventario de ellos y de llevar la contabilidad, rindiendo un informe periódico de su administración. Se supone que también vigilaba la conservación y el mejoramiento de la finca y quedaba facultado para celebrar contratos de arrendamiento por un año, anular o aprobar los existentes y nombrar empleados. Por concepto de arrendamiento de tierras de labranza y montes, se tomaba como

\footnotetext{
${ }^{78}$ Eran El Oso, Pilares, Cuevecillas, Mimbres, Culebras, Casa Colorada, Ayala, Santa Anita, Fray Diego, Granados, Soledad y Pacheco, RPPD, vol. 34 , insc. 5328 .

${ }^{79}$ Ibid.
} 
base para el cobro un $10 \%$ de los productos, y por arrendamiento de fincas urbanas, un $10 \%$ anual de sus valores fiscales. ${ }^{80}$

De este periodo existen datos sobre la hacienda de Tapona y sus ranchos anexos, ubicada en el municipio de Peñón Blanco, partido de Cuencamé, la que estuvo trabajada por tercieros que ponían las semillas, los bueyes o las mulas, las calzas de reja y su trabajo, según la costumbre local, y cuidada por un administrador nombrado por el Departamento de Bienes Interve. nidos, el cual percibía un sueldo de 75 pesos mensuales. En algunos de los ranchos pertenecientes a esta hacienda, los mismos soldados recogían las cosechas y, según informes del administrador, en otros, los peones "no querían trabajar por menos de un peso plata". ${ }^{81}$

Pero también hubo casos en que las intervenciones se hicieron sin autorización oficial de la Dirección de Bienes Intervenidos, como sucedió con la Hacienda de la Purísima y sus ranchos anexos, en el partido de Cuencamé, perteneciente a la testamentaría de Miguel García, la cual fue incautada en octubre de 1916 bajo el gobierno del general Gavira, "pero sin estar bajo control real de la Administración". La razón que se esgrimió por dicha ocupación fue que estaba abandonada. Durante el tiempo que esta hacienda estuvo intervenida, los parcioneros que la trabajaban entregaron al administrador la décima parte de las cose-

${ }^{80} \mathrm{Ibid}$.

${ }^{81} \mathrm{AGN}$, Bienes intervenidos, vol. $5 \mathrm{E}$, exp. 5. chas. ${ }^{82}$ Otro caso fue el del rancho El Maguey, en el municipio de Canatlán, propiedad de la Southwestern Realty Co., el cual fue confiscado personalmente en marzo de 1917 por el general Miguel Laveaga, quien manifestó tener poder para dividirlo, argumentando que él lo administraba para poderlo entregar a determinados indígenas, "herederos de los antiguos dueños que lo habían poseído hacía cientos de años". ${ }^{83}$

LAS DEVOLUCIONES Y La RECONCILIACIÓN CARRANCISTA (1917-1921)

Cuando Carranza asumió el control militar del movimiento, consideró necesario fortalecerse y, con miras más bien políticas que económicas, ofreció a los antiguos dueños la devolución de todas sus propiedades confiscadas. El fin inmediato aparente fue echar a andar la producción del campo, pero una razón de peso era contar con el apoyo de los hacendados. Con el propósito de llevar a efecto las devoluciones de las propiedades confiscadas, Carranza estableció una Administración General de Bienes Intervenidos, controlada por el gobierno central, la cual vigilaría los procesos de desintervención y tendría la última palabra en cuanto a las devoluciones definitivas.

Las confiscaciones se habían basado, desde la época de Rouaix, en los "antecedentes políticos" de los due-

\footnotetext{
${ }^{82}$ Fue autorizada su desintervención en septiembre de 1917, en $i b i d$., vol. 5E, exp. 6.

${ }^{83} \mathrm{AGN}$, Periodo revolucionario, vol. 222, exp. 25.
} 
ños. $Y$ cuando se iniciaron las investigaciones respectivas para llevar a cabo el proceso de desintervención, la posible devolución de haciendas y casas debía depender de dichos antecedentes. En Durango casi todos ellos terminaron por diluirse y la entrega de las propiedades confiscadas por los diferentes gobiernos revolucionarios marchó sin contratiempos. Sólo fueron retenidas aquellas que habían pertenecido al clero.

En general, los informes arrojaron que las confiscaciones hechas por las distintas comandancias militares y sus colaboradores más cercanos habían sido bastante arbitrarias, pues, como mencionó uno de los quejosos en su solicitud de desintervención: "me duele [...] la injusticia de que por el sólo hecho de no ser revolucionario, como no fui antes político, se me vengan a lanzar cargos que no merezco y que por lo tanto rechazo" ${ }^{84}$ La mayoría de los motivos de intervención había tenido un claro contenido de clase, y los afectados por la revolución lamentaban haber bajado su nivel de vida, como lo expresó el administrador de varias haciendas algodoneras en La Laguna quien, refiriéndose a su dueña, la señora María Luján de Terrazas, declaraba que sufría "la miseria en la ciudad de El Paso, Texas, haciendo personalmente sus labores de cocina, mientras su hija lavaba las ropas". 85

En realidad, las causas de la intervención resultaron ser casi las mismas. Según los datos que se recabaron en 1919 por la Administración de

${ }^{84}$ Ibid., vol, 188, exp. 40, 1917.

${ }^{85}$ Ibid., vol. 187, exp. 57, 1917.
Bienes Intervenidos, de las que se tenían registradas, la mayoría había sido por el decreto de julio de 1914 expedido por Pastor Rouaix contra el clero y por haber pertenecido a la Defensa Social. Pero también existían otras por motivos tan generales como "ser enemigo del gobierno", sin especificar cuál gobierno. En las actas notariales hechas con motivo de la devolución de propiedades se especificaba, en algunos casos, si habían sido confiscadas durante el gobierno de Rouaix o por los gobiernos villistas o carrancistas, o por las distintas comandancias militares. No obstante que no nos fue posible ubicar el momento en que se hicieron todas las confiscaciones, en la mayoría el motivo fue haber sido "enemigo de la revolución" y, como esgrimía uno de los afectados, éstos eran "los hombres de los grandes negocios". 86

En los listados del estado de Coahuila, en cambio, las causas resultaron ser más variadas y precisas: por ser enemigo del constitucionalismo; por haber sido funcionario del gobierno huertista; haber pertenecido a la Defensa Social huertista o al gobierno villista y, por tanto, ser "elemento activo de la facción"; haber sido agente financiero de Villa; por ser de la familia Madero y simpatizador de Huerta; por ser del clero; por haber huido y, por tanto, considerado enemigo de la causa. ${ }^{87}$ Es evidente que el informe de Coahuila, no por ser más explícito, es más fidedigno. En muchos casos saltan a la vista las informaciones falseadas, como el

\footnotetext{
${ }^{86}$ Ibid., vol. 187, exp. 57.

${ }^{87}$ Ibid., vol. 184, exp. 38.
} 
decir que a José Ma. Luján se le confiscó una propiedad por haber sido agente financiero de Villa, cuando otros documentos comprueban que muchas pertenencias de Luján y de su familia, ubicadas en la comarca lagunera, estuvieron intervenidas militarmente por los villistas. ${ }^{88}$

Mientras duraron las intervenciones, muchos miembros de la elite no sólo se vieron afectados en sus intereses, sino que al salir del estado se encontraron con pocos recursos y bajo amenaza de volver. Para noviembre de 1916, según informes del gobernador Gabriel Gavira al oficial mayor de Hacien$\mathrm{da}$, los principales "reaccionarios durangueños" que se encontraban fuera de la ciudad eran Rafael y Julio Bracho, Julio F. Curbelo, Jesús, José, Leandro y Luis Pérez Gavilán, Antonio Gurza, Antonio y Fráncisco Gómez Palacio, Eduardo Hartmann, Juan Lozoya, Esteban Fernández, Julián Medina y Juan Santa Marina ${ }^{89}$ casi todos residiendo en la colonia Juárez de la ciudad de México.

Si bien las desintervenciones en Durango se hicieron por órdenes firmadas por el propio Carranza, los procesos se resolvieron en su mayoría con criterios locales. El hecho de que las fincas fuesen o no devueltas, dependía de la comprobación de los "antecedentes y conductas políticas" de sus propietarios para juzgar quiénes eran

\footnotetext{
${ }^{88}$ Véase "Informe rendido al señor general
enustiano Carranza, primer jefe del ejército

${ }^{88}$ Véase "Informe rendido al señor general
Venustiano Carranza, primer jefe del ejército constitucionalista, encargado del poder ejecutivo de la nación por Jesús R. Ríos, Torreón, Coah., 24 de octubre de 1915", CONDUMEX, archivo Carranza, fondo XXI, carpeta 56.

${ }^{89} \mathrm{AGN}$, Periodo revolucionario, vol. 70, exp. 36, 1916.
}

"enemigos de la causa constitucionalista". Cuando se hicieron las solicitudes, en muchos casos, al no encontrarse ningún antecedente de peso político, el argumento se redujo a la afirmación de que, "con rarísimas excepciones, todo Durango fue enemigo de la causa", ${ }^{90}$ como sucedió en el proceso de devolución de la hacienda de Tapona y Anexas, propiedad de la señora Teodora Pastor Moncada, viuda de Blanco, ocupada desde el villismo y después intervenida durante el carrancismo. La mayoría, sin embargo, se refería al reparo de las injusticias cometidas por los villistas, y en la mayor parte de las investigaciones que se hicieron, las responsabilidades terminaron por ser atribuidas más al villismo que al carrancismo.

Carranza dispuso que en toda desintervención fuera levantada un acta ante notario y que al hacerse entrega de la propiedad la Dirección General de Bienes Intervenidos quedaba exenta, y por tanto el gobierno de la república, de cualquier responsabilidad que pudiera resultar con motivo de los daños y perjuicios sufridos por la finca entregada, durante el tiempo que estuvo intervenida.

En Durango la primera desintervención se hizo el 25 de mayo de 1916, y para marzo de 1919 se habían devuelto sus bienes a un total de 44 propietarios: 27 haciendas (doce en Mapimí, nueve en Gómez Palacio y una en Durango); un rancho en Durango; 56 casas, y varias propiedades del Banco Minero de Chihuahua, cuatro terrenos y una quinta en Gómez Palacio; 86 ca-

${ }^{90} \mathrm{AGN}$, Bienes intervenidos, caja 5E, exp. 5. 


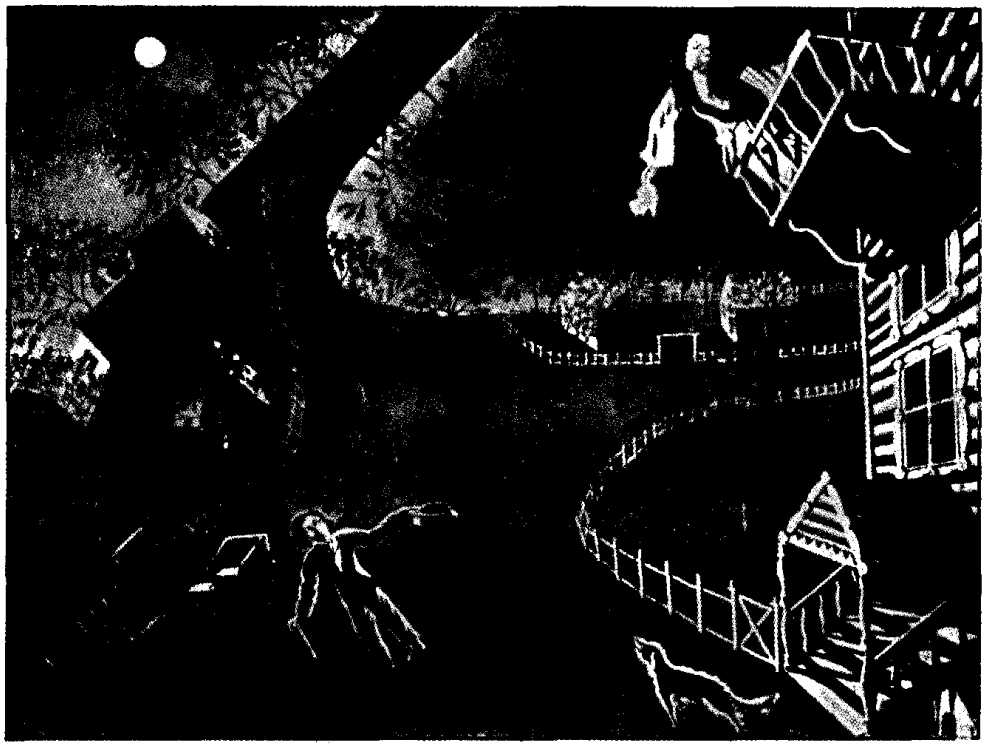

sas en Durango; una fábrica en Gómez Palacio, la empresa de Tranvías de Durango; cinco haciendas en Cuencamé y una capilla en ciudad Lerdo (véase cuadro 2)..$^{91}$

Algunas desintervenciones se hicieron bajo condiciones expresas. Por ejemplo, en el caso de Tapona, esta hacienda se devolvería siempre y cuando la dueña dejara una parte de la cosecha en fruto en manos de la Administración de Bienes Intervenidos, ${ }^{92}$ siendo

${ }^{91}$ AGN, Periodo revolucionario, vol. 191, exp. 5. En Coahuila se devolvieron alrededor de 165 casas, la mayoría en Torreón, cerca de 90 haciendas, como 50 terrenos y once ranchos. Ibid., vol. 184, exp. 38.

${ }^{92}$ AGN, Bienes intervenidos, vol. $5 \mathrm{E}$, exp. 5. por cuenta de ella los gastos originados en su recolección, o como con la finca de Santa Lucía, la cual se acordó desintervenir con la condición de que los dueños sostuvieran una escuela elemental primaria para los niños y niñas que habitaban la hacienda. ${ }^{93}$

En 1919 todavía se encontraban registradas como fincas rústicas intervenidas que adeudaban contribuciones: La Ochoa y Anexas en Poanas; Nombre de Dios, propiedad de Julio Bracho, con un valor fiscal de 71386 pesos "por enemigo del gobierno"; Palmitos, en la municipalidad de Rodeo, propiedad de María de J. Fierro, viuda de Villarreal, con valor fiscal de 51880

${ }^{93}$ Ibid., vol. 5E, exp. 7. 


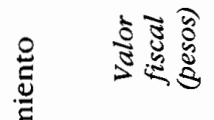

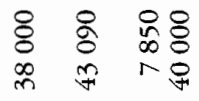

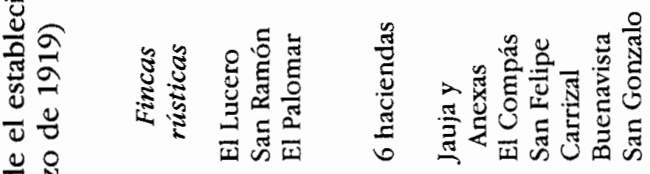

苋 :

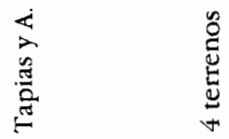

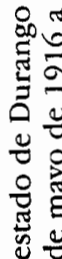

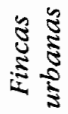

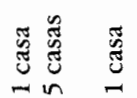

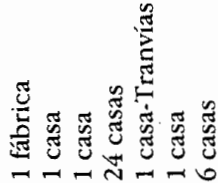

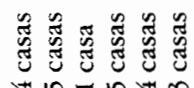

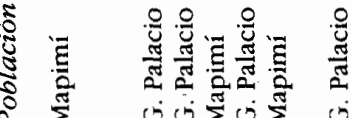

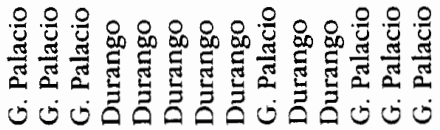

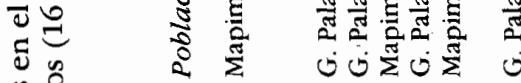

宽

늠

远

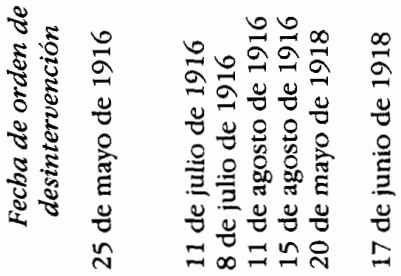

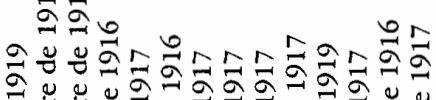

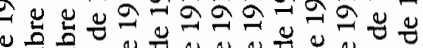

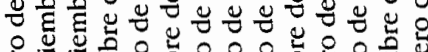

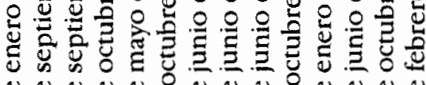

割

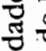

常

은

ปั

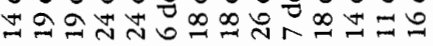

㝵

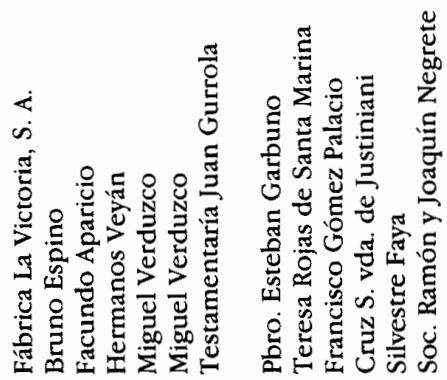




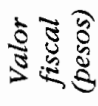

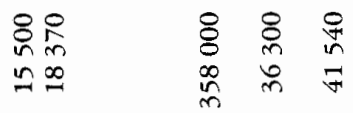

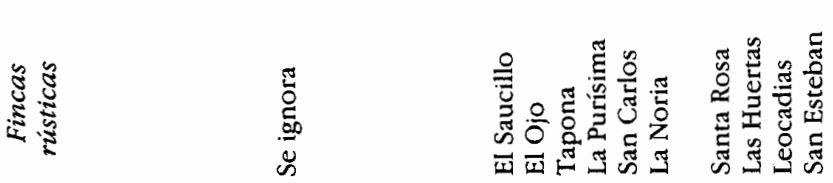

$\stackrel{5}{n}$

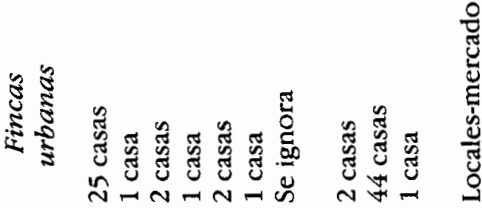

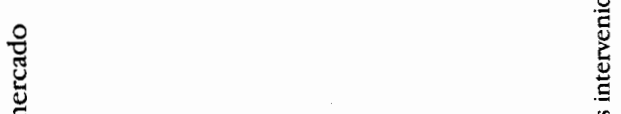

:

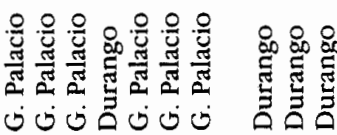

ن

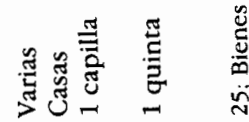

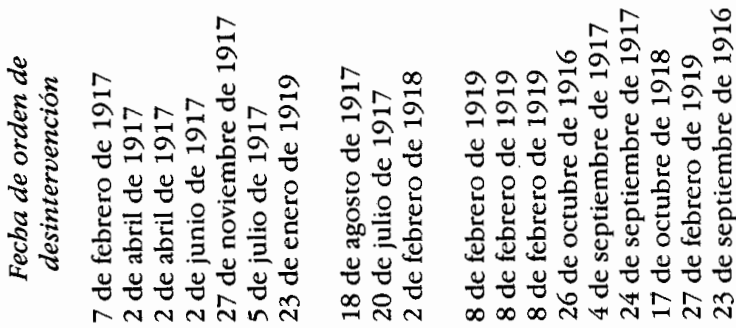

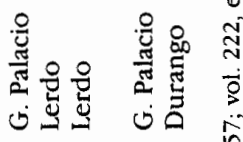

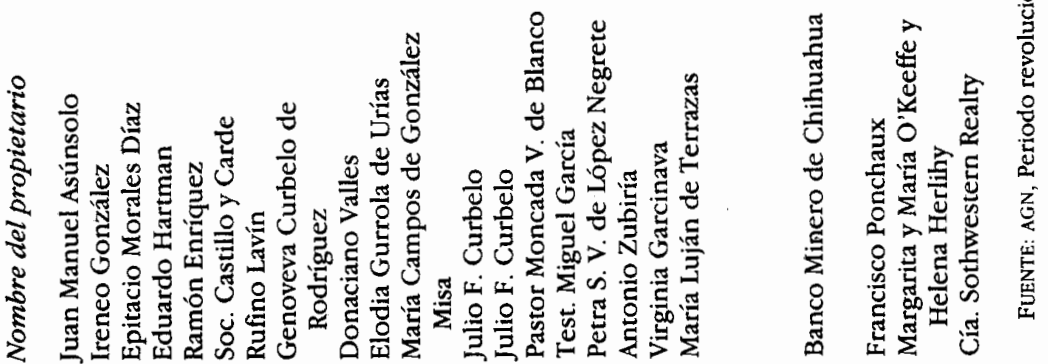


pesos, "por haber sido su hijo, jefe de la Defensa Social, según datos particulares"; la hacienda de Ramos propiedad de los canónigos Rafael López de Lara y J. Refugio Delgado, en la municipalidad de El Oro, con valor de 370150 pesos, "por ser del clero"; ${ }^{44}$ la hacienda de La Noria, en la municipalidad de Pánuco de Coronado, propiedad de Antonio Zubiría, con un valor fiscal de 42540 pesos. ${ }^{95}$

Mientras Carranza devolvía las propiedades confiscadas para atraerse sobre todo el apoyo de los hacendados, prometía al mismo tiempo repartir tierras a quien las solicitara. De acuerdo con la ley que había expedido el 6 de enero de 1915, los gobernadores y comandantes militares quedaron capacitados para restituir y dotar de ejidos a los pueblos; nombrar los comités locales para decidir y ejecutar provisionalmente las resoluciones, y a una comisión nacional para aprobar o negar la solicitud en términos definitivos. En diciembre de 1915 se instaló en Durango la Comisión Local Agraria, la cual se encargó de arreglar lo concerniente a la restitución y adjudicación de ejidos. Para fines de 1916 se habían enviado a la Comisión Nacional Agraria, a cuya cabeza figuraba Pastor Rouaix, poco más de diez expedientes de solicitud

\footnotetext{
${ }^{94}$ Las contribuciones de esta hacienda correspondientes a 1918 debían ser pagadas, la mitad correspondiente a todo el año por el general Miguel Aguirre y la mitad desde el 50. bimestre por la Administración de Bienes Intervenidos. Ibid., vol. 5E, exp. 8.

95 "Relación de las propiedades intervenidas que existen bajo el control de la Administración de Bienes Intervenidos en Durango", AGN, Periodo revolucionario, vol. 191, exp. 5 .
}

de tierras. Los casos que tuvieron resoluciones favorables durante los años de 1917 a 1920 se muestran en el cuadro 3 .

Fue hasta 1921 que se dio el decreto de restitución de tierras solicitada por los pueblos de Santiago y San Pedro de Ocuila, en Cuencamé, que tanto habían peleado por ellas, desde antes de la revolución, con los dueños de la hacienda de Sombreretillos y que durante todo el movimiento armado las tuvieron ocupadas. Lo mismo sucedió con los habitantes de Pasaje, pueblo enclavado en el latifundio de Santa Catalina del Álamo. ${ }^{96}$

En realidad, con estas resoluciones de restitución y dotación efectuadas durante los últimos años de la década, las grandes haciendas apenas fueron afectadas en su superficie, y la erección de pueblos libres suscitó una serie de conflictos en la entidad. En algunas partes, los propietarios de las fincas agredieron a los habitantes de los nuevos pueblos, como en el caso de la hacienda de Sacramento, en la municipalidad de Gómez Palacio, donde varios vecinos denunciaron "algunos ultrajes de que habían sido objeto por parte del dueño de la hacienda". ${ }^{97}$ En Pueblo Nuevo, el rico negociante Eduardo Hartmann, acompañado de un grupo de soldados, pretendió recuperar la posesión de los terrenos que el municipio ya consideraba como propiedad de los habitantes, y los soldados desarmaron a los miembros de la Defensa

\footnotetext{
${ }^{96}$ AGN, Comisión Nacional Agraria, Resoluciones presidenciales, Durango, vol. IX.

${ }^{97}$ Periódico Oficial, 30 de marzo de 1919.
} 
Cuadro 3. Solicitudes de tierras resueltas favorablemente por la Comisión Nacional Agraria

\begin{tabular}{|c|c|c|c|}
\hline & Municipio & $\begin{array}{l}\text { Extensión } \\
\quad \text { (ba) }\end{array}$ & Haciendas afectadas \\
\hline Avilés & Lerdo & 1775.61 & Avilés \\
\hline Sauces de Salinas & Peñón Blanco & 3511 & Santa Catalina y Tapona \\
\hline Bermejillo & Mapimí & 1775.61 & \\
\hline El Arenal & Durango ' & 1775.61 & $\begin{array}{l}\text { El Registro y San } \\
\text { Lorenzo del Aire }\end{array}$ \\
\hline Muleros & Súchil & 1775.61 & $\begin{array}{l}\text { La Luz, El Mortero, El Ancón, } \\
\text { El Molino y Santa Bárbara }\end{array}$ \\
\hline Contreras & Durango & 500 & Navacoyán y Dolores \\
\hline San José de Gracia & Canatlán & 1755.61 & $\begin{array}{l}\text { La Sauceda, Santa Lucía y } \\
\text { Potrero de Nogales }\end{array}$ \\
\hline Villa Madero & Pánuco & 1000 & Tapona \\
\hline
\end{tabular}

FUENTE: AGN, Comisión Nacional Agraria, Resoluciones presidenciales, Durango, vols. I, II, III, v y v.

Social del pueblo. ${ }^{98}$ Además, varios propietarios solicitaron juicio de amparo a la Suprema Corte de Justicia de la Nación contra la creación de nuevos pueblos, exigiendo además, que previamente se hiciera el pago de las indemnizaciones respectivas.

Con la llegada de Domingo Arrieta al gobierno constitucional de Durango en 1917 y debido a la política seguida por Carranza en el sentido de centralizar el control de las devoluciones de bienes confiscados para reactivar la producción del campo, los hacendados salieron ganando. Además, con esta medida el mismo Carranza contaría con el apoyo de las elites locales que esperaban recuperar su poder económico. En Durango muchos de los antiguos poderosos que habían sufrido

${ }^{98}$ Orientación, 23 de marzo de 1920. persecución, así como daños y confiscaciones en sus propiedades, nombraron representantes legales desde la ciudad de México para recibir sus bienes. Otros volvieron al estado después de que vieron desvanecerse el peligro.

Pese a que en 1918 el gobernador Arrieta se quejaba con Carranza de que la mayoría de los que habían vuelto eran connotados enemigos del constitucionalismo y que estaban obstruyendo la labor de su gobierno a través de los amparos que solicitaban a cada momento, ${ }^{99}$ finalmente terminó por alinearse con las disposiciones provenientes del centro y llevar a cabo una política de conciliación con los miembros de la antigua elite, quienes lograron colocarse en una buena posición ante el go-

${ }^{99}$ AHSDN, ramo Histórico, $\mathrm{XI} / 481.5 / 112,1918$, f. 131 . 
bernador, el cual, a su vez, fue bastante más benévolo con ellos que sus antecesores.

Podemos concluir que, si bien el proceso confiscatorio que se había llevado a cabo durante los años de revolución socavó el poder económico, sobre todo de la elite terrateniente, en realidad no puede decirse que haya ocasionado su ruina, y menos aún si contaban con otros negocios. Aunque una buena parte de las familias se desmembraron porque algunos de sus miembros no volvieron a Durango, muchos hacendados regresaron y retomaron sus actividades económicas de antes, pudiendo recuperarse lentamente. Otros sólo regresaron a vender sus propiedades o a fraccionarlas entre sus mismas familias para que sufrieran la mínima afectación en el reparto agrario. Lo que sí es claro es que casi todos perdieron su influencia política. La forma en que logró recuperarse lo que quedó de la antigua elite, así como las afectaciones que paulatinamente sufrieron en sus propiedades hasta la época del gran reparto cardenista, es otro tema a profundizar en investigaciones futuras.

Por ahora, podemos afirmar que la elite porfiriana se fue resquebrajando durante las distintas fases de la revolución en Durango, principalmente a través de los procesos confiscatorios de sus bienes. Sin embargo, más allá del desenlace final que trajo consigo el triunfo carrancista, con la consecuente reconciliación y el pacto implícito con ella al devolverle lo quitado, es evidente que durante los momentos de auge alcanzados por la revolución de los vencidos, en los que hubo una mayor disposición por solucionar las demandas sociales, algo se logró trastocar, lo cual demuestra que no fue menor el intento de acabar con lo que representaba el símbolo del poder de los terratenientes.

\section{ARCHIVOS}

\begin{tabular}{|c|c|}
\hline AGN & Archivo General de la Nación. \\
\hline $\mathrm{AGA}$ & Archivo General Agrario. \\
\hline ASDN & $\begin{array}{l}\text { Archivo de la Secretaría de la } \\
\text { Defensa Nacional. }\end{array}$ \\
\hline CONDUMEX & $\begin{array}{l}\text { Centro de Estudios de His } \\
\text { toria de México, ConDumEX. }\end{array}$ \\
\hline INAH & $\begin{array}{l}\text { Instituto Nacional de Antro- } \\
\text { pología e Historia. }\end{array}$ \\
\hline AHSRE & $\begin{array}{l}\text { Archivo Histórico de la Secre- } \\
\text { taría de Relaciones Exteriores }\end{array}$ \\
\hline NAW & $\begin{array}{l}\text { National Archives Washing } \\
\text { ton. }\end{array}$ \\
\hline AHGED & $\begin{array}{l}\text { Archivo Histórico del Gobier } \\
\text { no del Estado de Durango. }\end{array}$ \\
\hline RPPD & $\begin{array}{l}\text { Registro Público de la Pro } \\
\text { piedad de Durango. }\end{array}$ \\
\hline ASTJD & $\begin{array}{l}\text { Archivo del Supremo Tribu- } \\
\text { nal de Justicia de Durango. }\end{array}$ \\
\hline
\end{tabular}

\section{HEMEROGRAFÍA}

-Periódico Oficial del Gobierno del Estado de Durango, 1913-1920.

-La Unión Liberal, 1914, Durango.

-La Voz de la Revolución, 1915, Durango.

-La Época, 1916, Durango.

-El Mañana, 1912, México.

-Orientación, 1920, Durango.

\section{BIBLIOGRAFÍA}

-Altamirano, Graziella, "Los años de revolución" en Altamirano, Mebius, Navarro y Villa, Durango. Una bistoria compartida, Instituto Mora, México, 1997, t. II. 
"El maderismo en Durango.

Lucha política e intentos de democracia. 1910-1913" en Porfiriato y revolución en Durango, Universidad Juárez del Estado de Durango, Durango, 1999.

-Barragán I., Juan y Mario Cerutti, Brittingham y la industria en México. 1859. 1940, Urbis Internacional, Monterrey, 1993.

-Colección de leyes, decretos y circulares del gobierno revolucionario de $\mathrm{Du}$ rango expedidas durante el periodo comprendido del 4 de julio de 1913 al 7 de agosto de 1914 por el gobernador provisional C. Ing. Pastor Rouaix, Talleres Gráficos de la Secretaría de Fomento, México, 1917.

-Gavira, Gabriel, General de brigada, Gabriel Gavira. Su actuación politico-militar revolucionaria, Talleres Tipográficos de A. del Bosque, México, 1933.

-Katz, Friedrich, "Pancho Villa, los movimientos campesinos y la reforma agraria en el norte de México" en David Brading, Caudillos y campesinos en la revolución mexicana, FCE, 1985.

1998, 2 vols.

-Knight, Alan, La revolución mexicana, Grijalbo, México, 1996, 2 vols.

-Parra Durán, Lorenzo, Cómo empezó

la revolución en Durango bace veinte años, Talleres de la Compañía Tipográfica Yucateca, Mérida, Yuc., 1930.

-Pazuengo, Matias, Historia de la revolución en Durango, Tipografía del Gobierno del Estado, Cuernavaca, Mor., 1915.

-Reed, John, México insurgente, Ariel, Barcelona, 1971.

-Rouaix, Pastor, La revolución maderista y constitucionalista en Durango, Editorial Cultura, México, 1931.

-Ulloa, Bertha, Historia de la revolución mexicana. 1914-1917, El Colegio de México, México, 1979, vol. 5.

- Vargas Arreola, Juan B., A sangre y fuego con Pancho Villa, Fondo de Cultura Económica, México, 1988.

-Walker, David W., "Homegrown revolution: the hacienda Santa Catalina del Âlamo y Anexas and agrarian protest in eastern Durango, México, 1897-1913", Hispanic American Historical Review, vol. 72, núm. 2, Duke University Press, 1992.

$\longrightarrow$, 'Y hay que quedar conforme porque a nadie se le puede exigir nada': the villista legacy $\&$ agrarian radicalism in eastern Durango, México, 19131930", ponencia presentada en el congreso The Revolution of the Vanquished, Chicago, 10-12 de mayo de 1996. 